\title{
Article
}

\section{Chromophore/DNA Interactions: Femto- to Nanosecond Spectroscopy, NMR Structure, and Electron Transfer Theory}

Till von Feilitzsch, Jennifer Tuma, Heike Neubauer, Laurent Verdier, Reinhard Haselsberger, Reiner

Feick, Gagik Gurzadyan, Alexander A. Voityuk, Christian Griesinger, and Maria E. Michel-Beyerle J. Phys. Chem. B, 2008, 112 (3), 973-989• DOI: 10.1021/jp0764050 • Publication Date (Web): 29 December 2007

Downloaded from http://pubs.acs.org on March 24, 2009

\section{More About This Article}

Additional resources and features associated with this article are available within the HTML version:

- $\quad$ Supporting Information

- Access to high resolution figures

- $\quad$ Links to articles and content related to this article

- $\quad$ Copyright permission to reproduce figures and/or text from this article

\section{View the Full Text HTML}




\title{
Chromophore/DNA Interactions: Femto- to Nanosecond Spectroscopy, NMR Structure, and Electron Transfer Theory
}

\author{
Till von Feilitzsch,,$"$, Jennifer Tuma,,$\$$ Heike Neubauer, ${ }^{\S}$ Laurent Verdier, \\ Reinhard Haselsberger, ${ }^{\dagger}$ Reiner Feick, ${ }^{\dagger}$ Gagik Gurzadyan,${ }^{\dagger}$ Alexander A. Voityuk, ${ }^{\perp}$

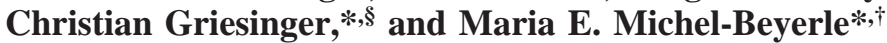 \\ Physikalische Chemie, Department Chemie, Technische Universität München, Lichtenbergstr. 4, 85748 \\ Garching, Germany, Max-Planck-Institut für Biophysikalische Chemie, Am Fassberg 11, 37077 Göttingen, \\ Germany, Centre d'Etudes du Bouchet BP 391710, 91710 Vert Le Petit, France, and Institució Catalana de \\ Recerca i Estudis Avancats (ICREA), Institute of Computational Chemistry, Universitat de Girona, Spain
}

Received: August 9, 2007; In Final Form: October 30, 2007

\begin{abstract}
The mechanism of photoinduced hole injection into DNA has been studied using an integrated approach that combines NMR structural analysis, time-resolved spectroscopy, and quantum-chemical calculations. A covalently linked acridinium derivative, the protonated 9-amino-6-chloro-2-methoxyacridine $\left(\mathrm{X}^{+}\right)$, is replacing a thymine and separated from either guanine $(\mathrm{G})$ or the easier to oxidize 7-deazaguanine $(\mathrm{Z})$ by one adenine thymine $(\mathrm{A} \cdot \mathrm{T})$ base pair. The key features of this donor/acceptor system are the following: (i) In more than $95 \%$ of the duplexes, $\mathrm{X}^{+}$is located in a central, coplanar position between the neighboring $\mathrm{A} \cdot \mathrm{T}$ base pairs with its long axis in parallel showing minimal twist and tilt angles $\left(<15^{\circ}\right)$. The complementary adenine base is turned out into the extrahelical space. In a minority of less than $5 \%, \mathrm{X}^{+}$is found to be still attached to the duplex. $\mathrm{X}^{+}$is most probably associated with one of the phosphates, since it is neither intercalated between more remote base pairs nor bound to sugars or grooves. This minority characterized by an excited state lifetime $>10 \mathrm{~ns}$ gives rise to a small background signal in time-resolved measurements and contributes predominantly to steady-state fluorescence spectra. (ii) Although the intercalation mode of $\mathrm{X}^{+}$is well defined, the NMR structure reveals that there are two conformations of $\mathrm{X}^{+}$with respect to the arrangement of its methoxy substituent. In one conformation, the methoxy group is in the plane of the chromophore, while, in the other extraplanar conformation, the methoxy group forms an angle of $70^{\circ}$ with the acridinium ring. The fluorescence decay of $5^{\prime}$-ZAX and 5'-GAX tracts can be fitted to a biexponential function with similar amplitudes, reflecting the oxidation dynamics of $\mathrm{G}$ and $\mathrm{Z}$, with the slower rate being determined by larger thermal activation energy. The attribution of biexponential electron transfer (ET) dynamics to the bimodal orientation of the methoxy group at the acridinium is supported by quantum-chemical calculations. These predict a larger free energy change for hole transfer in the nonplanar conformation as compared to the planar one, whereas the difference in the electronic couplings is negligible. (iii) Kinetic studies of the directionality of the ${ }^{1}\left(\mathrm{X}^{+}\right)^{*}$ induced hole injection reveal similarly fast decay components in both directions of the duplex, that is, in $5^{\prime}$-ZAX and $5^{\prime}$-XAZ, with the amplitude of the fast component being significantly reduced in $5^{\prime}$-XAZ. The NMR structure shows that local structural deviations from B-DNA are much more pronounced in the $3^{\prime}-5^{\prime}$ direction than in the $5^{\prime}-3^{\prime}$ direction. According to quantum-chemical calculations, the directionality of charge injection is not a universal feature of the DNA duplex but depends critically on the rotation angle of the aromatic plane of the acridinium within the $\pi$ stack. The arrangement of $\mathrm{X}^{+}$in $5^{\prime}$-ZAX and $5^{\prime}$-XAZ corresponds to a conformation with weak directionality of the electronic couplings. The increased disorder in the $3^{\prime}-5^{\prime}$ direction favors slow hole transfer components at the expense of the fast ones. (iv) A comparison of the hole transfer in $5^{\prime}$-GAX and 5'-ZAG shows that classical Marcus theory can explain the ratio of the charge shift rates of more than 2 orders of magnitude on the basis of a free energy difference between $G$ and $\mathrm{Z}$ of $0.3 \mathrm{eV}$. Both NMR structures and quantum-chemical calculations justify the appreciable neglect of differences of electronic couplings as well as in the reorganization energy in 5'-GAX and 5'-ZAG. Despite the attractive concept for the behavior of floppy DNA oligonucleotides, in this acridinium/DNA system, there is no evidence for conformational gating, that is, for fluctuations in the electronic couplings that permit the ET to occur.
\end{abstract}

\section{Introduction}

The early conjecture of wirelike charge transport in doublestranded DNA ${ }^{1}$ was resurrected in the early $1990 \mathrm{~s}^{2}$ in order to

* Corresponding authors.

$\dagger$ Technische Universität München.

$\ddagger$ These authors contributed equally to this work.

$\S$ MPI für Biophysikalische Chemie, Göttingen.

"Centre de Physico-Chimie et Biotechnologies, Reims.

$\perp$ Universitat de Girona. explain charge transfer between redox probes attached to opposite ends of a DNA duplex which were over $40 \AA$ apart. This experiment and subsequent reports on long-range oxidative damage of guanines ${ }^{3,4}$ stimulated widespread research activities which were also challenged by the emergent fields of DNAbased biosensors and nanoelectronics. As a result, due to the design of novel functionalized DNA systems and improved ways of diagnostics complemented by theoretical modeling, there has been real progress. ${ }^{5,6}$ The vast majority of steady-state experi- 
ments on charge transport in DNA pertains to the motion of an electron hole localized on guanine $(\mathrm{G})$ across a tunneling barrier defined by the other nucleobases adenine (A), thymine (T), and cytosine $(\mathrm{C})$ that have higher lying energy levels and, at least in solution, are more difficult to oxidize. ${ }^{7,8}$ The relative rates ( $k$ ) of single-step hole motion between guanines show a strong distance $(R)$ dependence ${ }^{9}$ falling off exponentially with an attenuation factor of $\beta \sim 0.7 \mathrm{~A}^{-1}$ in $k(R) \sim \exp (-\beta R)$ as long as the number of intervening $\mathrm{A} \cdot \mathrm{T}$ base pairs is small $(n<4){ }^{10}$ The (nearly) exponential distance dependence of the relative electron transfer (ET) rates suggests that donor/acceptor couplings involve the off-resonance $\mathrm{A} \cdot \mathrm{T}$ bridge states in a superexchange mechanism. ${ }^{9,11-13}$ In contrast to this single-step ET process, long-range hole transport shows only a weak distance dependence. ${ }^{8,10}$ The widely accepted basic concept for modeling long-range charge transport in the DNA rests on weakly distance-dependent, thermally activated charge hopping. ${ }^{11-13}$

At this stage of insight, one overarching question is whether conventional theory is capable of treating ET rates in DNA, or whether the unique environment and the inherent complexity of the duplex due to fluctuations of nucleobases and associated water molecules and ions call for improvement and extensions of the theoretical models. ${ }^{14}$ Although it was possible to explain the gross features of photoinduced single-step oxidation of guanine in stilbene/DNA hairpins ${ }^{15}$ and acridinium-modified duplexes ${ }^{16,17}$ within the framework of Marcus-Levich-Jortner ET theory, ${ }^{18}$ this was not possible when ethidium was used as photooxidant, supporting the notion of conformational gating of the electronic couplings by structural fluctuations on the time scale of $10-100$ ps. $^{19}$

With this background in mind, we revisit in the following the dynamics of a single-step hole-shift reaction initiated by an acridinium derivative, the protonated 9-amino-6-chloro-2-methoxyacridine $\left(\mathrm{X}^{+}\right) \cdot{ }^{16,17}$ Apart from complementing our previous femtosecond absorption data by fluorescence measurements, this paper is an attempt to understand ET dynamics of this specific hole injection in the light of an NMR structural analysis and quantum-chemical calculations. We mention in passing that in recent years acridine derivatives have experienced a revival in connection with mismatch recognition, ${ }^{20}$ telomerase inhibition, ${ }^{21}$ and protein labeling. ${ }^{22}$

As indicated in Chart 1 , the acridinium $\left(\mathrm{X}^{+}\right)$is covalently attached to the sugar-phosphate backbone. Previous studies ${ }^{16,17}$ showed that within the lifetime of its excited state ${ }^{1}\left(\mathrm{X}^{+}\right) *$ is not able to oxidize adenine due to the relatively high oxidation potential of the latter. Nevertheless, ${ }^{1}\left(\mathrm{X}^{+}\right) *$ may well accept an electron from the purines $\mathrm{G}$ and its analogue 7-deazaguanine (Z) where the replacement of the N7-atom of $\mathrm{G}$ by $\mathrm{CH}$ increases the driving force for the reduction of ${ }^{1}\left(\mathrm{X}^{+}\right)^{*}$ by $0.2-0.4 \mathrm{eV}$, as concluded from experiments, ${ }^{24,25}$ modeling of kinetics, ${ }^{10 \mathrm{c}}$ and quantum chemistry. ${ }^{26,27}$ In contrast to stilbene/DNA hairpins where the attenuation factor for single-step ET was found to be similar to the one obtained from the Giese systems, ${ }^{10}$ for $\mathrm{X}^{+} / \mathrm{DNA}$ systems, this factor is unusually large $(\beta \geq 1.5$ $\left.\AA^{-1}\right) .16,17$

This feature together with the masking of the ground state return process upon increasing the distance between $\mathrm{X}^{+}$and the purine base indicates that, in addition to the electronic couplings, the activation energy must also be distance-dependent. This postulate is independently supported by the temperature dependence of the charge shift rates for a series of $\mathrm{X}^{+}$-modified DNA duplexes which sample donor-acceptor distances between 3.4 and $11.2 \AA .{ }^{17 \mathrm{~b}}$ The resulting changes in thermal activation energy have been explained within the framework of classical
CHART 1: Scheme of DNA Duplexes with the Positions of Nucleobase Exchange Indicated Together with the Structures of the Purine Bases Guanine (G) and 7-Deazaguanine $(Z)$, the Spacer $(d)$, and the Protonated 9-Amino-6-chloro-2-methoxyacridine $\left(\mathrm{X}^{+}\right)$Tethered by a $-\left(\mathrm{CH}_{2}\right)_{6}$-Linker Directly to the Backbone and Not via a Peptide Bond as in Previous Work ${ }^{16,23}$
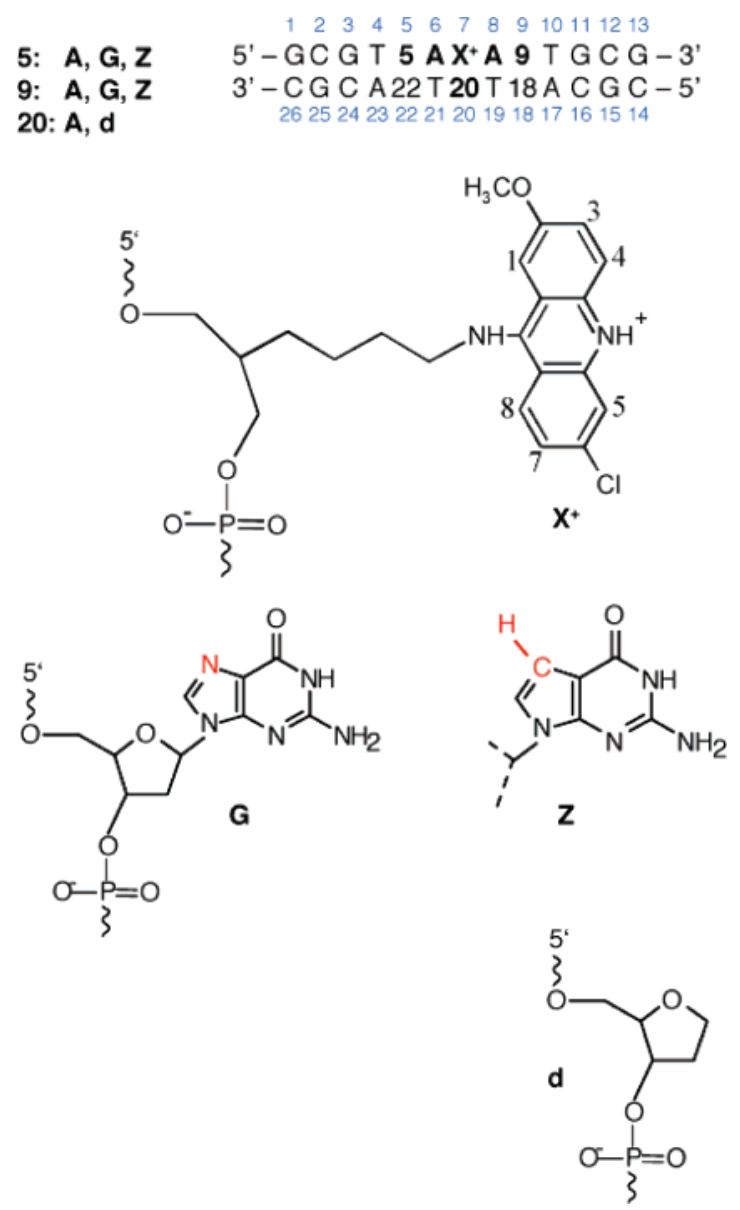

Marcus theory ${ }^{28}$ in terms of a distance-dependent medium reorganization energy.

We will focus in this paper on three problems, with (i) and (ii) being related to the performance of conventional theory describing ET in DNA and (iii) addressing the potential influence of the helical structure of the DNA duplex on the directionality of ET.

(i) Although the increased activation energy of the hole injection rate upon increasing the number of $\mathrm{A} \cdot \mathrm{T}$ base pairs from $n=1$ to $n=2$ in the sequence $5^{\prime}$-ZAX can be explained by an increase of the medium reorganization energy for a charge shift in the normal range of the Marcus formalism, ${ }^{28}$ it is confusing that, concluded from transient absorption measurements, the ground state return reaction $\left(\mathrm{Z}^{+}\right)^{\bullet} \mathrm{AX} \cdot \rightarrow \mathrm{ZAX}^{+}$ driven by a large free energy change $(>2.4 \mathrm{eV})$ seems to be even more thermally activated. ${ }^{17}$ This observation is in contrast to both experimental evidence ${ }^{29}$ and theory ${ }^{28}$ predicting a negligibly small activation energy for ET in the inverted Marcus regime. For completeness of the argument, more detailed information is given in Appendix A.

(ii) Another issue to be reexamined is the former result that, based on rates and activation energies, ${ }^{17}$ the electronic couplings of the forward charge shift reaction $5^{\prime}-\mathrm{ZA}^{1}\left(\mathrm{X}^{+}\right)^{*} \rightarrow 5^{\prime}-\left(\mathrm{Z}^{+}\right)^{\bullet}-$ $\mathrm{AX}^{\bullet}$ seem to be larger than those for the canonical sequence $5^{\prime}-\mathrm{GA}^{1}\left(\mathrm{X}^{+}\right)^{*} \rightarrow 5^{\prime}-\left(\mathrm{G}^{+}\right)^{\bullet} \mathrm{AX} \bullet$ by more than a factor of 3 . If this 
TABLE 1: Acridinium-Modified Duplexes according to Chart 1 Together with Melting Points

\begin{tabular}{|c|c|c|}
\hline & sequence & melting point \\
\hline $5^{\prime}-\mathrm{AAX}$ & $\begin{array}{l}5^{\prime} \text {-GCG TAA } \mathbf{X}^{+} \text {AAT GCG-3' } \\
3^{\prime} \text {-CGC ATT A TTA CGC-5' }\end{array}$ & $56^{\circ} \mathrm{C}$ \\
\hline $5^{\prime}$-AAT & $\begin{array}{l}5^{\prime} \text {-GCG TAA T AAT GCG-3' } \\
3^{\prime} \text {-CGC ATT A TTA CGC-5' }\end{array}$ & $54{ }^{\circ} \mathrm{C}$ \\
\hline $5^{\prime}-\mathrm{GAX}$ & $\begin{array}{l}5^{\prime}-\text { GCG TGA X } \\
3^{\prime}-\text { A AC AC ACT A TTA CGC-5' }\end{array}$ & $61{ }^{\circ} \mathrm{C}$ \\
\hline $5^{\prime}$-GAT & $\begin{array}{l}5^{\prime}-\text { GCG TGA T AAT GCG-3' } \\
3^{\prime} \text {-CGC ACT A TTA CGC-5' }\end{array}$ & \\
\hline $5^{\prime}$-ZAX & $\begin{array}{l}5^{\prime} \text {-GCG TZA X }{ }^{+} \text {AAT GCG-3' } \\
3^{\prime} \text {-CGC ACT A TTA CGC-5' }\end{array}$ & $61{ }^{\circ} \mathrm{C}$ \\
\hline $5^{\prime}$-ZAT & $\begin{array}{l}\text { 5'-GCG TZA T AAT GCG-3' } \\
3^{\prime} \text {-CGC ACT A TTA CGC-5' }\end{array}$ & \\
\hline $5^{\prime}-Z_{A X}$ & $\begin{array}{l}5^{\prime}-\text { GCG TZA X }{ }^{+} \text {AAT GCG-3' } \\
3^{\prime}-\text { CGC ACT d TTA CGC- } 5^{\prime}\end{array}$ & \\
\hline $5^{\prime}-X A Z$ & $\begin{array}{l}5^{\prime} \text {-GCG TAA } \mathbf{X}^{+} \text {AZT GCG-3' } \\
3^{\prime} \text {-CGC ATT A TCA CGC-5 }{ }^{\prime}\end{array}$ & \\
\hline $5^{\prime}$-ZAXAZ & $\begin{array}{l}5^{\prime} \text {-GCG TZA X }{ }^{+} \text {AZT GCG-3' } \\
3^{\prime} \text {-CGC ACT A TCA CGC-5' }\end{array}$ & $64^{\circ} \mathrm{C}$ \\
\hline
\end{tabular}

was true, we would expect pronounced differences in the structures of $5^{\prime}$-GAX and $5^{\prime}$-ZAX showing up in an NMR structural analysis. On the other hand, quantum-chemical calculations ${ }^{30}$ performed on the triplets $3^{\prime}$-AZT and $3^{\prime}$-AGT point to similar electronic couplings.

(iii) Quantum-chemical calculations of the electronic coupling matrix elements for hole transfer in idealized B-DNA exhibit pronounced directional asymmetry arising solely from the helical structure of the duplex. For instance, the coupling matrix element in $5^{\prime}-\mathrm{GA}-3^{\prime}$ is about 5 times larger than that of $3^{\prime}-\mathrm{GA}-5^{\prime} .{ }^{30}$ Directional charge transfer in the DNA duplex has been studied experimentally in a variety of DNA-based donor/acceptor systems, and conclusions range from no effect ${ }^{16 \mathrm{~d}, 31-33}$ to hole transfer favored both in the $3^{\prime}-5^{\prime}$ direction ${ }^{16,34,35}$ and in the opposite $5^{\prime}-3^{\prime}$ direction. ${ }^{26}$ These conflicting results may reflect differences in the electronic couplings brought about by the molecular nature of the various charge donors and their position toward the base stack. Alternatively, structural perturbations on the part of the nucleobases or a superposition of both effects may prevail. Thus, also, here structural information is required to discriminate between a genuine effect of the helical structure and structural distortions induced by the intercalator.

The family of DNA duplexes studied in this paper is compiled in Table 1. In all cases, the protonated acridinium $\mathrm{X}^{+}$replacing a thymine is flanked by identical $\mathrm{A} \cdot \mathrm{T}$ base pairs. As we consider the various facets of the NMR structure together with ET kinetics and theory, the paper is organized in six sections. The materials and methods are described in section 2. The NMR structural characterization of the system is given in section 3 followed by steady-state and femto/picosecond fluorescence and absorption measurements in section 4 . On the basis of the structure of the acridinium binding site, the body of kinetic data is discussed in section 5, including the assignment of the multiexponential fluorescence decay pattern and the application of ET theory complemented by quantum-chemical calculations. Concluding remarks are given in section 6 . There are three appendices showing details of the analysis. Supplementary experimental data are collected in the Supporting Information.

\section{Materials and Methods}

Materials. 9-Amino-6-chloro-2-methoxyacridinium in $\mathrm{X}^{+}$labeled DNA single strands and their counterstrands were purchased in a lyophilized state after polyacrylamide gel electrophoresis (PAGE) purification. For most of the absorption and fluorescence measurements and all NMR studies, $\mathrm{X}^{+}$- containing single strands were separated by high pressure liquid chromatography (HPLC) into two fractions of diastereomers differing in the stereochemistry of the $\mathrm{X}^{+}$-nucleoside analogue (Biospring). This procedure was necessary due to the prochirality of the $\mathrm{X}^{+}$nucleoside. Single-stranded oligomers were dissolved in sodium phosphate buffer $(100 \mathrm{mM}, \mathrm{pH} 7)$ and added to an equivalent amount of the complementary $\mathrm{X}^{+}$-labeled oligomer. The duplex was formed by annealing at $80{ }^{\circ} \mathrm{C}$ for $10 \mathrm{~min}$ and cooling down to room temperature within $2 \mathrm{~h}$. The formation of the double strand was confirmed by measuring 1D-imino NMR spectra using a mixture of $90 \% \mathrm{H}_{2} \mathrm{O}$ and $10 \% \mathrm{D}_{2} \mathrm{O}$. For the experiments carried out in $\mathrm{D}_{2} \mathrm{O}$, dsDNA $(1.5 \mathrm{mM})$ was lyophilized and dissolved in $300 \mu \mathrm{L}$ of $99.999 \% \mathrm{D}_{2} \mathrm{O}$ (Deutero).

Most of the UV-vis steady-state and time-resolved studies were performed on the NMR samples without any changes. Whenever different samples were studied, stock solutions of both single strands (Eurogentec) were dissolved at $500 \mu \mathrm{M}$ in a different buffer solution ${ }^{17}\left(10 \mathrm{mM} \mathrm{Na} \mathrm{HPO}_{4} / \mathrm{NaH}_{2} \mathrm{PO}_{4}, 150\right.$ $\mathrm{mM} \mathrm{NaCl}, \mathrm{pH}$ 7.2) and results did not differ from the one obtained with the NMR samples. In order to form the DNA duplex $(250 \mu \mathrm{M})$, these solutions were mixed with a $10 \%$ excess of counterstrand and subjected to annealing using the same procedure as that used for the NMR samples.

NMR Spectroscopy. All NMR experiments were performed at $800 \mathrm{MHz}$ on a DRX800 spectrometer (Bruker) equipped with an $\mathrm{O} 2$ Silicon Graphics workstation. 1D-imino spectra were acquired for checking the duplex formation. In addition, the number of $\mathrm{H} 5$ and $\mathrm{H} 6$ cytosine aromatic protons was counted for the dye-labeled dsDNA and its reference to verify structural homogeneity. Standard procedures for the assignment of DNA resonances were used relying on the correlation of chemical shifts of protons either via through bond scalar couplings $(J-$ couplings) or nuclear Overhauser enhancement (NOE). The ${ }^{1} \mathrm{H}$ NOESY spectra ${ }^{36-38}$ in $\mathrm{D}_{2} \mathrm{O}$ were obtained with mixing times of 100 and $150 \mathrm{~ms} ; 4096 \times 512$ data points were recorded in nuclear Overhauser and exchange spectroscopy (NOESY) as well as in correlation spectroscopy (COSY). ${ }^{39}$ The spectral width in the NOESY as well as in the COSY spectra was $7.8 \mathrm{ppm}$. A total of 48 scans per $t_{1}$ value was recorded. The relaxation delay was $2.0 \mathrm{~s}$. The spectra were processed on an Origin200 Silicon Graphics workstation using the program XWINNMR (Bruker, Karlsruhe, version 3.1). A $90^{\circ}$-shifted squared sine bell window function was applied for apodization prior to Fourier transformation in both dimensions. Automated baseline correction was applied in both dimensions. All spectra were obtained at 274 and $308 \mathrm{~K}$, and all chemical shifts were referenced to the signal for residual HDO in the 2D NOESY spectrum at $4.73 \mathrm{ppm}$ at $308 \mathrm{~K}$. Concentrations of $\mathrm{X}^{+} / \mathrm{DNA}$ samples were adjusted to $0.3 \mathrm{OD}$ in the maximum of $\mathrm{X}^{+}$absorption.

Structure Calculations. The peaks in the NOESY spectrum recorded at $150 \mathrm{~ms}$ were integrated. The calculated interproton distances were calibrated on the basis of the cytosine H5, H6 cross-peaks and are shown in Table 2 for exemplary protonproton distances involving $\mathrm{X}^{+}$protons. A correction of 0.5 or $1.0 \AA$ was added to the lower and upper bounds of the distance restraints. The NOE integral $(I)$ has been converted into a distance of $r$ taking the H5/H6 NOE integrals $\left(I_{\mathrm{H} 5 / \mathrm{H} 6}\right)$ of the cytosines as a reference with a distance of $r_{\mathrm{H} 5 / \mathrm{H} 6}=2.48 \AA$ according to $r=r_{\mathrm{H} 5 / \mathrm{H} 6}\left(I_{\mathrm{H} 5 / \mathrm{H} 6} / I\right)^{1 / 6}$ and are given in Table 2. All structure calculations were performed using the CNS_SOLVE 1.0 program. The starting B-form of the 13 mer duplex bound to $\mathrm{X}^{+}$by a 2-hydroxymethyl-6-aminohexanol linker was built using INSIGHT II 2000.1 (Accelrys, San Diego, CA). The force field of the B-DNA was taken from the RNA-DNA-ALLATOM 
TABLE 2: Observed NOEs between Protons of the Acridinium $\mathrm{X}^{+}$and Nucleotides

\begin{tabular}{llc}
\hline & & distance $(\AA)$ \\
\hline $\mathrm{H}^{\prime}(\mathrm{T} 21)$ & $\mathrm{OMe}\left(\mathrm{X}^{+}\right)$ & 2.6 \\
$\mathrm{H} 6(\mathrm{~T} 21)$ & $\mathrm{OMe}\left(\mathrm{X}^{+}\right)$ & 4.0 \\
$\mathrm{H} 4^{\prime}(\mathrm{T} 21)$ & $\mathrm{OMe}\left(\mathrm{X}^{+}\right)$ & 4.1 \\
$\mathrm{H}^{\prime} / 5^{\prime \prime}(\mathrm{T} 21)$ & $\mathrm{OMe}\left(\mathrm{X}^{+}\right)$ & 3.8 \\
$\mathrm{H}^{\prime}(\mathrm{A} 6)$ & $\mathrm{H} 7 / \mathrm{H} 8\left(\mathrm{X}^{+}\right)$ & 4.7 \\
$\mathrm{H} 1^{\prime}(\mathrm{A} 6)$ & $\mathrm{H} 7 / \mathrm{H} 8\left(\mathrm{X}^{+}\right)$ & 3.8 \\
$\mathrm{H} 8(\mathrm{~A} 6)$ & $\mathrm{H} 7 / \mathrm{H} 8\left(\mathrm{X}^{+}\right)$ & 4.0 \\
$\mathrm{H} 2^{\prime} / \mathrm{H} 2^{\prime \prime}(\mathrm{A} 6)$ & $\mathrm{H} 7 / \mathrm{H} 8\left(\mathrm{X}^{+}\right)$ & 3.1 \\
$\mathrm{H} 3 / \mathrm{H} 4\left(\mathrm{X}^{+}\right)$ & $\mathrm{Me}(\mathrm{T} 21)$ & 4.1 \\
$\mathrm{H} 3 / \mathrm{H} 4\left(\mathrm{X}^{+}\right)$ & $\mathrm{H} 1^{\prime}(\mathrm{T} 21)$ & 4.1
\end{tabular}

parameter file for nucleic acids. The parameters used for dye and linker were derived from the standard DISCOVER 3.0/ INSIGHT II CVFF force field. ${ }^{40}$

The initial conformer was subjected to a simulated annealing protocol consisting of three steps: an initial 15 ps hightemperature phase at $2000 \mathrm{~K}$ was followed by a 15 ps cooling phase, where the temperature was lowered to $0 \mathrm{~K}$ in steps of $50 \mathrm{~K}$, and finally by three cycles of 500 conjugate gradient minimization steps. A total of 149 NOE-derived distance restraints (139 intra-DNA and 10 DNA-dye restraints) was applied with soft-square potential and using force constants of $200 / 200 / 100 \mathrm{kcal} \cdot \mathrm{mol}^{-1} \cdot \AA^{-2}$ during the three steps. The hydrogen bonds were deduced from the characteristic shift values of the aminoprotons in the NMR spectra and included as restraints in the molecular dynamics calculations. Additional planarity restraints using a force constant of $600 \mathrm{kcal} \cdot \mathrm{mol}^{-1}$ were included to maintain the geometry of base rings. The base planarity restraint file was built exclusively for bases, showing in experiments no chemical shift deviation when compared to a canonical B-DNA.

Using a homemade CNS_SOLVE 1.0 module (based on the original prot.f sources), we included the calculation of ring current shifts using the Haigh and Mallion formulas. ${ }^{41}$ The chemical shift difference between the DNA-dye resonances (5'-AAX) and the reference B-DNA resonances (5'-AAT) was assumed to be mainly due to the magnetic susceptibility of the aromatic rings of the bases when moving and of the $\mathrm{X}^{+}$when inserting into the helix. We did not take into account the effects of possible hydrogen bonding mismatches. The energy was computed as a harmonic potential, $E^{\mathrm{rcs}}=k\left(d^{\mathrm{rcs}}-d_{0}{ }^{\mathrm{rcs}}\right)^{2}$, where $k$ is the force, $d^{\text {rcs }}$ is the ring current shift of the computed structure, and $d_{0}{ }^{\mathrm{rcs}}$ is the ring current shift of the reference canonical B-DNA. ${ }^{42,43}$ We used force constants of 800/800/400 $\mathrm{kcal} \cdot \mathrm{mol}^{-1} \cdot \mathrm{ppm}^{-2}$ during the three steps. The differences in chemical shift between $5^{\prime}$-AAX and its unmodified analogue 5 -AAT extracted from the experimental spectra as well as derived from the lowest energy structure calculated on the basis of NMR restraints are shown in the Supporting Information (Figure S1.1).

Steady-State Optical Spectroscopy. Absorption spectra and melting experiments were recorded with a Perkin-Elmer Lambda $2 \mathrm{~S}$ and a Varian Cary 100 Bio spectrometer. The spectral resolution of both systems was $2 \mathrm{~nm}$ or better. Steady-state fluorescence and fluorescence excitation spectra were measured with a Spex Fluorolog-2 model F212I spectrofluorometer with a spectral resolution of $1.7 \mathrm{~nm}$ resolution or better. The temperature was adjusted in an LN2 flow cryostat.

Femtosecond/Picosecond Time-Resolved Fluorescence. Depending on the relevant time window for probing, three different methods were employed to follow the decay of fluorescence: time-resolved single photon counting (TCSPC), ${ }^{44}$ streak camera, ${ }^{44}$ and fluorescence upconversion. In all cases, the relative polarization between the excitation and fluorescence beams was set to the magic angle by a thin film polarizer.

Time Correlated Single Photon Counting (TCSPC). The sample was excited by the output of a Ti:sapphire oscillator (Coherent Mira) pumped with $8 \mathrm{~W}$ by an $\mathrm{Ar}^{+}$laser (Coherent Innova 310). The emission wavelength of the Ti:sapphire oscillator was tuned to $840 \mathrm{~nm}$ and frequency-doubled to 420 $\mathrm{nm}$. The repetition rate of the excitation pulses was reduced to 3.8 MHz with a pulse picker (Coherent model 9200). The detection wavelength of the emitted fluorescence light was selected by two double grid monochromators (Jobin Yvon H10) and detected on a multichannel plate. The time resolution of the apparatus was of the order of $30 \mathrm{ps}$ and limited by the electronic response.

Streak Camera Measurements. Fluorescence lifetimes shorter than 50 ps were recorded by a synchroscan streak camera (Hamamatsu C1576) using the same laser system for excitation as that used for TCSPC with a repetition rate of the excitation pulses of $76 \mathrm{MHz}$. In this detection periphery, the emission wavelength was selected with interference filters, typically with a spectral bandwidth of $20 \mathrm{~nm}$. The time resolution is limited to around 6 ps.

Fluorescence Upconversion. Fluorescence was excited by the second harmonic of a mode-locked Ti:sapphire laser (Coherent MIRA) pumped with a cw $\mathrm{Ar}^{+}$laser (Coherent INNOVA 310, $7.5 \mathrm{~W}$ ): wavelength $400 \mathrm{~nm}$, average power $50-150 \mathrm{~mW}$, pulse width $150 \mathrm{fs}$, pulse repetition rate $76 \mathrm{MHz}$. After collecting the fluorescence $(450-600 \mathrm{~nm})$ by parabolic mirror, it was

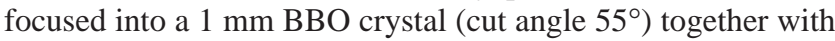
the fundamental radiation $(800 \mathrm{~nm}, 200 \mathrm{~mW})$ to generate the sum-frequency radiation. The resulting radiation $(290-340 \mathrm{~nm})$ was focused onto the entrance slit of a monochromator equipped with a 1200 grooves/mm grating blazed at $350 \mathrm{~nm}$ (Jobin Yvon, H10 UV) and detected by a photomultiplier (Hamamatsu H8259). The output signal was processed by photon counting electronics (Hamamatsu M8784). The apparatus function (full width at half-maximum (fwhm) $250 \mathrm{fs}$ ) was determined by measuring the cross-correlation between the fundamental and the Raman line in methanol $\left(2800 \mathrm{~cm}^{-1}\right)$.

Femtosecond Time-Resolved Absorption Spectroscopy. Transient absorption measurements were performed using a commercial Ti:sapphire oscillator/regenerative amplifier system (Coherent/BMI) with a time resolution better than $200 \mathrm{fs}$ and a repetition rate of $1 \mathrm{kHz}$. This laser system has been described in detail previously. ${ }^{45,46}$ Briefly, to generate pump pulses at 455 $\mathrm{nm}$, the output of the amplifier system at $780 \mathrm{~nm}$ was frequencydoubled and used to pump an optical parametric oscillator, followed by a two-step optical parametric amplifier (OPG/ OPA, BMI Venturi II). With this apparatus, we were able to produce $150 \mathrm{fs}$ pulses at $455 \mathrm{~nm}$ with $1 \mu \mathrm{J}$ energy. Probe pulses with variable time delay relative to the pump pulse were used to measure the transient absorption produced by the pump pulses. The probe pulses were generated by selecting a $15 \mathrm{~nm}$ wide portion out of a white light continuum generated by focusing $1-2 \mu \mathrm{J}$ pulses at $780 \mathrm{~nm}$ in a $2 \mathrm{~mm}$ sapphire crystal. Their polarization was at the magic angle $\left(54.7^{\circ}\right)$ in order to avoid contributions from orientational motion of the monitored molecules. The temperature of the samples was controlled using a water-flow-type thermostat.

\section{Structural Characterization of the $X^{+} /$DNA Duplex}

Melting Behavior. Hybridization of oligomers is confirmed by sigmoidal melting curves (Supporting Information Figure S1.2) showing for all duplexes a hypochromicity of $\sim 20 \%$ 


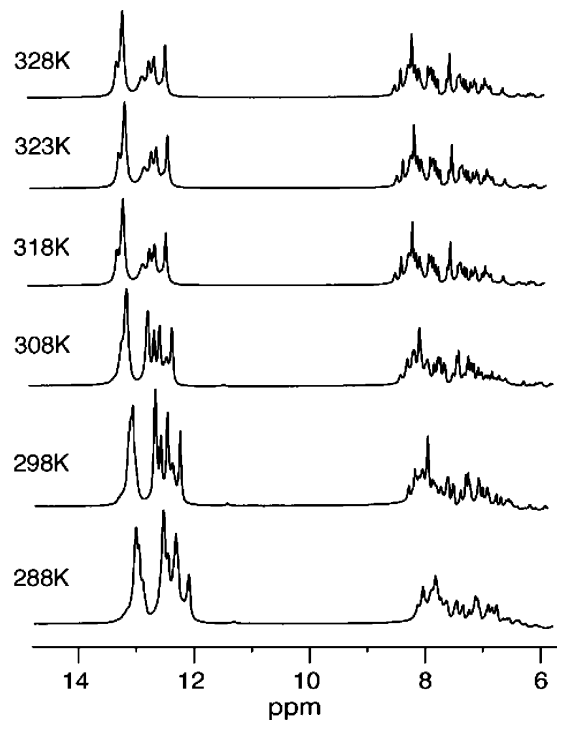

Figure 1. Temperature dependence of 1D NMR spectra of 5'-AAX.

independently of probing it in the region of nucleobase (260 $\mathrm{nm}$ ) or $\mathrm{X}^{+}$absorption $(438 \mathrm{~nm})$. As previously reported ${ }^{16 \mathrm{~b}, 17 \mathrm{a}}$ and measured for representative sequences in Table 1, replacement of thymine by $\mathrm{X}^{+}$leads to a slight increase of the melting point by $1-2 \mathrm{~K}$. This effect of structural stabilization of the duplex may be attributed to strong $\pi \pi$ interactions between $\mathrm{X}^{+}$ and the neighboring nucleobases. Such a tight binding situation is also supported by induced circular dichroism (CD) spectra of the achiral acridinium and is also consistent with the increase of vibronic structure of optical spectra of $\mathrm{X}^{+}$bound to the duplex as compared with $\mathrm{X}^{+}$in aqueous solution ${ }^{47}$ (vide infra).

NMR Spectroscopy of $\mathbf{5}^{\prime}$-AAX. Temperature Dependence of NMR Spectra. As to be expected and shown in Figure 1, the resolution of NMR resonances increases toward higher temperatures. The best resolution was achieved at $308 \mathrm{~K}$. The presence of the imino protons in the Watson-Crick region shows that the duplex $5^{\prime}$-AAX (melting point $56^{\circ} \mathrm{C}$ ) is still intact. Therefore, the following NMR experiments are performed at $308 \mathrm{~K}$. Furthermore, it is demonstrated that the NMR resonances at 308 and $288 \mathrm{~K}$ are comparable, indicating no significant change in structure.

Assignment of the Proton Resonances. The two diastereomers show almost identical chemical shifts and NOE patterns. It should be noted that kinetic experiments on a sample with mixed diastereomers do not differ significantly from control experiments on chirally separated samples. The $\mathrm{H}^{\prime}, \mathrm{H} 2^{\prime}, \mathrm{H} 2$, base, and imino DNA proton resonances were assigned using conventional approaches as described elsewhere. ${ }^{48}$ Further NMR resonances were assigned ambiguously due to the broadened lines and overlap of signals. A set of NMR spectra, such as total correlation spectroscopy (TOCSY), COSY, NOESY, and heteronuclear single quantum coherence (HSQC) spectra, allowed for the assignment of the proton resonances to the components of the system, the ribose backbone, the individual nucleobases, and the $\mathrm{X}^{+}$modification.

On the basis of NOESY spectra, it was possible to identify the $\mathrm{H}^{\prime}, \mathrm{H} 2^{\prime}$, and $\mathrm{H}^{\prime \prime}$ sugar proton resonances of all bases. Furthermore, using standard procedures, the NMR spectra provided the identification of the resonances of the methyl groups of the thymidines, the $\mathrm{H} 5 / \mathrm{H} 6$ base proton resonances of the cytosines, and the $\mathrm{H} 8$ base proton resonances of the purines for all bases except the ones neighboring $\mathrm{X}^{+}$(1 to 5, 9 to 18 , and 23 to 26). The methyl groups and $\mathrm{H} 6$ base protons of T21 and T22 could only be assigned from the intraresidual

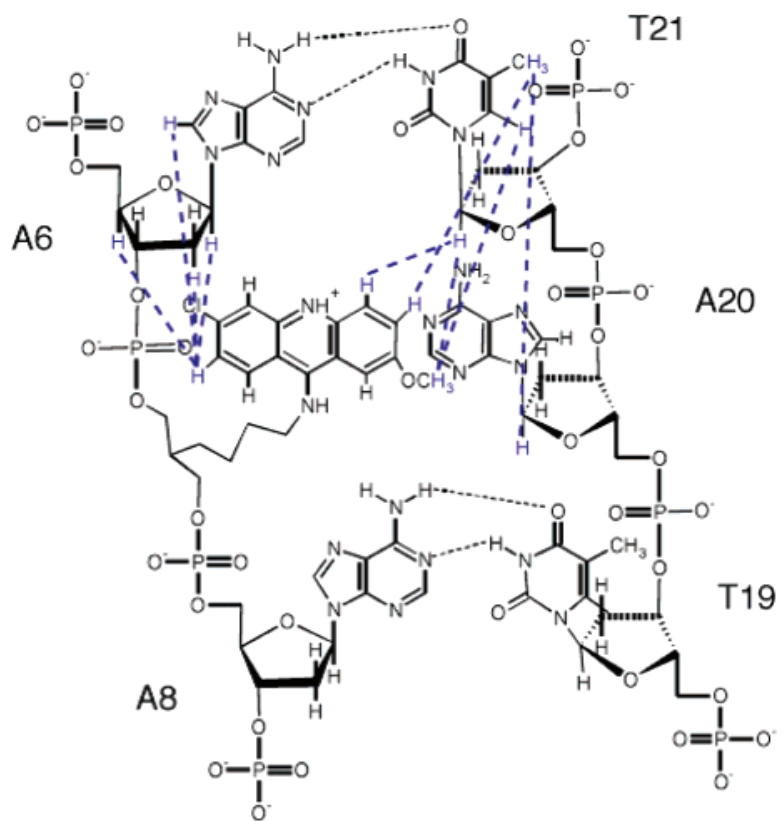

Figure 2. NOE resonances between protons of $\mathrm{X}^{+}$and its environment. These resonances allow the position of $\mathrm{X}^{+}$to be determined between the base pairs A6•T21 and A8・T19.

cross-peaks of these protons in the TOCSY spectrum with a spinlock time of $55 \mathrm{~ms}$; the sugar protons associated with T21 and T22 are assigned on the basis of NOESY spectra. It turned out to be quite difficult to distinguish the protons of $\mathrm{X}^{+}$from the protons of the neighboring bases with the exception of A6. Nevertheless, a HSQC spectrum that correlates with aromatic carbon resonances allowed this distinction, since the carbon resonances of $\mathrm{X}^{+}$appeared at a higher field than the resonances of the three adenines and the shifts induced by the ring current are minor on the scale of carbon chemical shifts. It should be emphasized that $\mathrm{H} 8$ of A20 shows only the canonical intranucleotide but not the canonical sequential NOEs. Due to overlap with the T18 resonances, the only base not assigned is T19. However, for both T18 and T19, the imino bridges to their respective counterbases are observed and the resonances of the sugar protons indicate a canonical structure of these bases. It should be emphasized that the imino-hydrogen bonds are observed for all base pairs, except the terminal ones due to fraying.

$\mathrm{X}^{+}$and Its Neighborhood. On the basis of this analysis of the NMR spectra, a B-DNA-type duplex can be assumed even in the absence of structure calculations, except for the immediate environment of $\mathrm{X}^{+}$. No NOE peaks could be observed for the counterbase to $\mathrm{X}^{+}, \mathrm{A} 20$. This distortion is further supported by differences of the chemical shifts of the sugar $\mathrm{H}^{\prime}$ protons of A20 when comparing the sequences $5^{\prime}$-AAX and $5^{\prime}$-AAT (Supporting Information Figure S1.1). As expected, the extrahelical position of A20 is reflected also in a relatively large perturbation of the backbone.

The position of $\mathrm{X}^{+}$is defined by NOE resonances to protons of neighboring bases and backbone on both strands of the duplex (Figure 2). As the $\mathrm{H} 7 / \mathrm{H} 8$ protons and the methoxy group of $\mathrm{X}^{+}$show cross-peaks with protons of the neighboring bases and their sugars, $\mathrm{X}^{+}$must be intercalated between the base pairs A6 $\cdot \mathrm{T} 21$ and A8 $\cdot \mathrm{T} 19$. This NMR pattern is observed for almost all duplexes $(>95 \%)$. A set of minority signals $(<5 \%)$ is assigned to $\mathrm{X}^{+}$not intercalated but still associated with the duplex, since resonances of $\mathrm{X}^{+}$free in solution, $\mathrm{X}^{+}$bound to grooves or sugars, or $\mathrm{X}^{+}$intercalated between the more remote 
base pairs are not observed. We call this the $\mathrm{X}^{+} / \mathrm{DNA}$ loose complex. In the HSQC spectrum, nine $\mathrm{H}, \mathrm{C}$ cross-peaks are detected for $\mathrm{X}^{+}$while only six are expected. The proton resonances of these additional HSQC cross-peaks were not involved in NOESY cross-peaks, also indicating that the small $\mathrm{X}^{+}$subpopulation is neither bound to grooves or sugars nor intercalated between base pairs other than between base pairs A6•T21 and A8•T19. Thus, $\mathrm{X}^{+}$is most probably associated with the negatively charged phosphates.

The missing NOEs between base protons of A20, the counterbase to $\mathrm{X}^{+}$, and neighboring bases T19 and T21 are indicative for an extrahelical position of A20. This view is supported by an interruption of the usual sequential assignment of inter- and intraresidual NOE resonances between $\mathrm{H}^{\prime}{ }^{\prime}$ and H6/H8 protons. Altogether, the number of cross-peaks between the $\mathrm{X}^{+}$and the neighboring bases is sufficient to crudely define the location of the dye but is insufficient for a more detailed analysis of the structure. Therefore, additional NMR parameters had to be taken into account.

Directionality of Structural Perturbations. Information on the directionality of structural perturbations around $\mathrm{X}^{+}$is derived from the line width of proton resonances (Supporting Information Figure S1.3). The proton resonances of the nearby adenines (A20, A6, and A8) and T21 show an increased line width as compared to the ones pertaining to bases more than two positions away from $\mathrm{X}^{+}$. It should be emphasized that the line broadening for the bases toward the $3^{\prime}$ end is substantially larger than that for the bases toward the $5^{\prime}$ end for both strands. The increased line width indicates that there is a conformational heterogeneity on a time scale of milliseconds to microseconds. Since these times are much longer than the longest fluorescence decay time $(19 \mathrm{~ns})$ of ${ }^{1}\left(\mathrm{X}^{+}\right) *$ in the sequences of Table 1 , they appear as static structural heterogeneities in the hole transfer kinetics. The line width of the base protons from A5 could not be determined; for T18 and T19, only an upper limit of the line width could be determined due to resonance overlap. Furthermore, we take into account the differences between chemical shifts of base protons in 5'-AAX and the reference 5'-AAT duplexes in order to compensate for the missing NOE restraints in this region of the duplex.

Calculations of the 5'-AAX Duplex Structure. Extrapolation on the Structures of 5'-GAX and 5'-ZAX. In order to assess the relevant coordinates underlying a three-dimensional structure, calculations have been performed on the basis of the constraints derived from the NMR data. A superimposed representation of the 10 lowest energy structures out of 200 calculated structures is shown in Figure 3. These structures constrained by the NMR results confirm the view that $\mathrm{X}^{+}$is intercalated at position 7 and its counterbase A20 is pushed out of the helix occupying unknown positions. As illustrated in Figure 3, the position of $\mathrm{X}^{+}$with respect to the base pairs is better defined in the $5^{\prime}$ direction than in the $3^{\prime}$ direction. It will be shown that this directionality of structural distortion also shows up in ET dynamics.

The overall deviation (rmsd) calculated from all heavy atoms amounts to $0.5 \AA$, except for the A20 nucleotide. The twist angle between an axis fixed in the planes of the base A5 and $\mathrm{X}^{+}$ differed by less than $15^{\circ}$. The tilt angle between the plane of $\mathrm{X}^{+}$and the helical axis differed by less than $10^{\circ}$. The distribution is statistical, and not determined by distinct subpopulations. In this respect, these features contrast to the orientation of the methoxy group. An analysis of the 10 lowest energy structures exhibited a bimodal distribution of conformations with a ratio of populations of $7: 3$, one with the methoxy
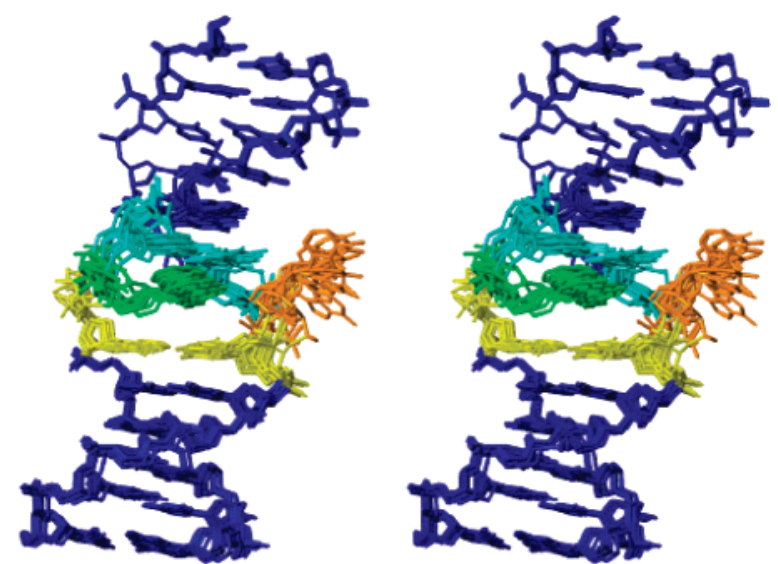

Figure 3. Stereorepresentation of the overlay of the 10 lowest energy structures of 5'-AAX obtained from restrained molecular dynamics calculations. The structures were superimposed by minimizing the distances of the heavy atoms with the exception of those belonging to $\mathrm{X}^{+}$. Green: $\mathrm{X}^{+}$replacing thymine. Orange: The counterbase A20. Yellow and turquoise: The base pairs A6•T21 and A8•T19.

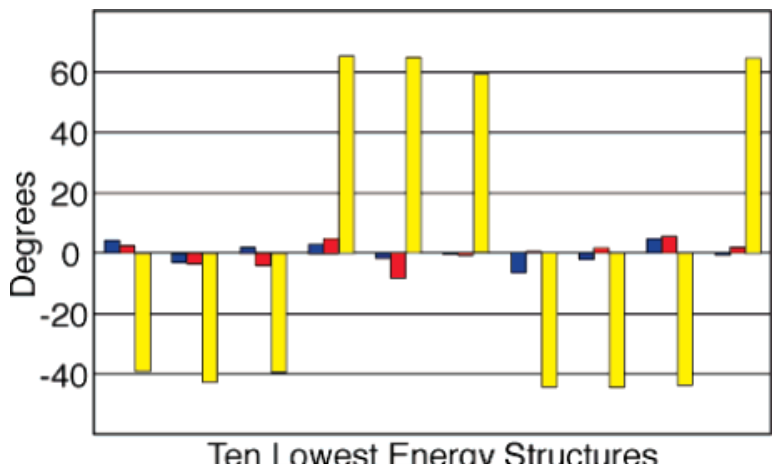

Figure 4. Specific features of the 10 lowest energy structures in terms of deviation from the mean. Orientation of the methoxy group with respect to the molecular plane of the acridinium $\mathrm{X}^{+}$(yellow) and of the entire chromophore with respect to the helical axis in terms of tilt (blue) and twist (red).

group $\mathrm{O}-\mathrm{CH}_{3}$ located in the plane of the acridinium ring, corresponding to a $\mathrm{C}_{\text {Ring }}-\mathrm{O}-\mathrm{CH}_{3}$ torsion angle of $180^{\circ}$ and one extraplanar conformation with a $\mathrm{C}_{\text {Ring }}-\mathrm{O}-\mathrm{CH}_{3}$ torsion angle of $70^{\circ}$ (Figure 4).

In the context of the charge injection kinetics and mechanisms, information on structural changes upon replacement of A5 in $5^{\prime}$-AAX by $G$ or the easier to oxidize $\mathrm{Z}$ is of primary importance. Since chemical shifts (Supporting Information Figure S1.4) and NOESY spectra (Figure 3) of the duplexes 5'-AAX, 5'-GAX, and 5'-ZAX are almost invariant, we assume that structural differences in these sequences are negligibly small.

Important Features of the $X^{+} / D N A$ Structure. For the first time, we present a structure of an acridine-labeled DNA complex, where in a central location of the duplex the dye serves as a base surrogate. On the basis of NMR data and molecular dynamics calculations, the acridinium $\mathrm{X}^{+}$occupies an abasic site replacing thymine and is in van der Waals contact with the neighboring base pairs, while its counter base A20 is flipped to an extrahelical position. Structural inhomogeneities are related to (i) a bimodal distribution of conformations with respect to the torsional angle formed by the methoxy substituent to the molecular plane of the acridinium and (ii) the immediate environment of the acridinium with respect to a pronounced deviation from B-DNA in the $3^{\prime}-5^{\prime}$ direction. Finally, it was also possible to identify a small population of $\mathrm{X}^{+} / \mathrm{DNA}$ loose 
complex $(<5 \%)$ in which the acridinium does not form any specific noncovalent contacts to the DNA duplex. Since neither intercalation of the acridinium between more remote base pairs nor binding to grooves or sugars is the dominant contribution to the minority signal, it is assumed that this originates from $\mathrm{X}^{+}$that is bound to a negatively charged phosphate. The new structure presented in this paper differs from earlier NMR studies on duplexes where the acridinium was not located in an abasic site but either intercalated between adjacent base pairs, ${ }^{49-52}$ bound in grooves, or capping the duplex. ${ }^{53,54}$

\section{Optical Spectroscopy}

Steady-State Absorption and Fluorescence Spectra. The absorption and fluorescence spectra shown in Figure 6 are representative for all $\mathrm{X}^{+}$-modified duplexes studied in this paper. The $S_{0}-S_{1}$ absorption spectrum shows bands centered at 452,428 , and $405 \mathrm{~nm}$ separated by $\sim 1250 \mathrm{~cm}^{-1}$. These bands are attributed to vibronic splitting, probably reflecting a vibration of the heterocyclic ring structure. In fluorescence, a mirror image of the absorption spectrum is observed showing a central peak at $499 \mathrm{~nm}$ and two side bands at 471 and $530 \mathrm{~nm}$ independent of the excitation wavelength. The significant increase in fine structure of the absorption and fluorescence spectra of $\mathrm{X}^{+}$bound to the duplex as compared to $\mathrm{X}^{+}$in solution is indicative of an organized environment. While the vibronic structure of the absorption spectra is independent of the particular sequence, there is some loss of fine structure in the fluorescence spectrum going from $5^{\prime}$-GAX and $5^{\prime}$-AAX to 5'-ZAX (vide infra).

The CD spectra of all duplexes listed in Table 1 display a positive band peaking at $277 \mathrm{~nm}$, a negative band at $250 \mathrm{~nm}$, and a crossover around $260 \mathrm{~nm}$, pointing to an overall B-form DNA structure. With respect to the local definition of the chromophore, much more important is the observation of an induced CD spectrum, as depicted in Figure 7.55 The negative features follow the mirror image of the $\mathrm{S}_{0}-\mathrm{S}_{1}$ absorption bands, while the positive band around $350 \mathrm{~nm}$ corresponds to the $\mathrm{S}_{0}-\mathrm{S}_{2}$ transition. Since the induced CD spectrum of the achiral acridinium arises from strong interactions of its electronic transition moments with the chirally arranged transition moments of the neighboring nucleobases, its observation is a strong support of $\mathrm{X}^{+}$intercalated within the base stack and thus confirms results of the NMR studies (section 3 ).

Dynamics of Excited State Decay, Hole Injection, and Back Transfer. As depicted in Figure 8, the fluorescence decay profiles of ${ }^{1}\left(\mathrm{X}^{+}\right)^{*}$ in the sequences $5^{\prime}$-AAX, 5'-GAX, and $5^{\prime}$-ZAX depend strongly on the base at position 5 being either $\mathrm{A}, \mathrm{G}$, or $\mathrm{Z}$. In contrast to these sequences where $\mathrm{Z}$ is located in the $5^{\prime}$ direction from $\mathrm{X}^{+}$, in $5^{\prime}$-XAZ the direction is reversed whereas in $5^{\prime}$-ZAXAZ the electron donor $\mathrm{Z}$ is in a symmetric configuration.

$5^{\prime}-A A^{l}\left(X^{+}\right) *$. Considering the sequence $5^{\prime}$-AAX, the fluorescence decay followed in TCSPC with a time resolution of 30 ps can be fitted monoexponentially to $19.2 \mathrm{~ns}$, confirming earlier data on similar or identical 5'-AAX sequences. ${ }^{16 \mathrm{~d}, 17}$ Broad-band pump-probe experiments ${ }^{56}$ revealed that the time scale of the Stokes shift, that is, of solvation of ${ }^{1}\left(\mathrm{X}^{+}\right)^{*}$ by neighboring $\mathrm{A} \cdot \mathrm{T}$ base pairs, is faster than $200 \mathrm{fs}$ and that there is no indication of further excited state relaxation up to $5 \mathrm{~ns}$, that is, within the time window of the measurements.

Recent hole injection experiments in stilbene hairpins ${ }^{57}$ suggest that the difference in oxidation potentials adenine and guanine may be as small as $0.2 \mathrm{eV}$, that is, similar to the difference between the oxidation potentials of $\mathrm{G}$ and $\mathrm{Z}$.
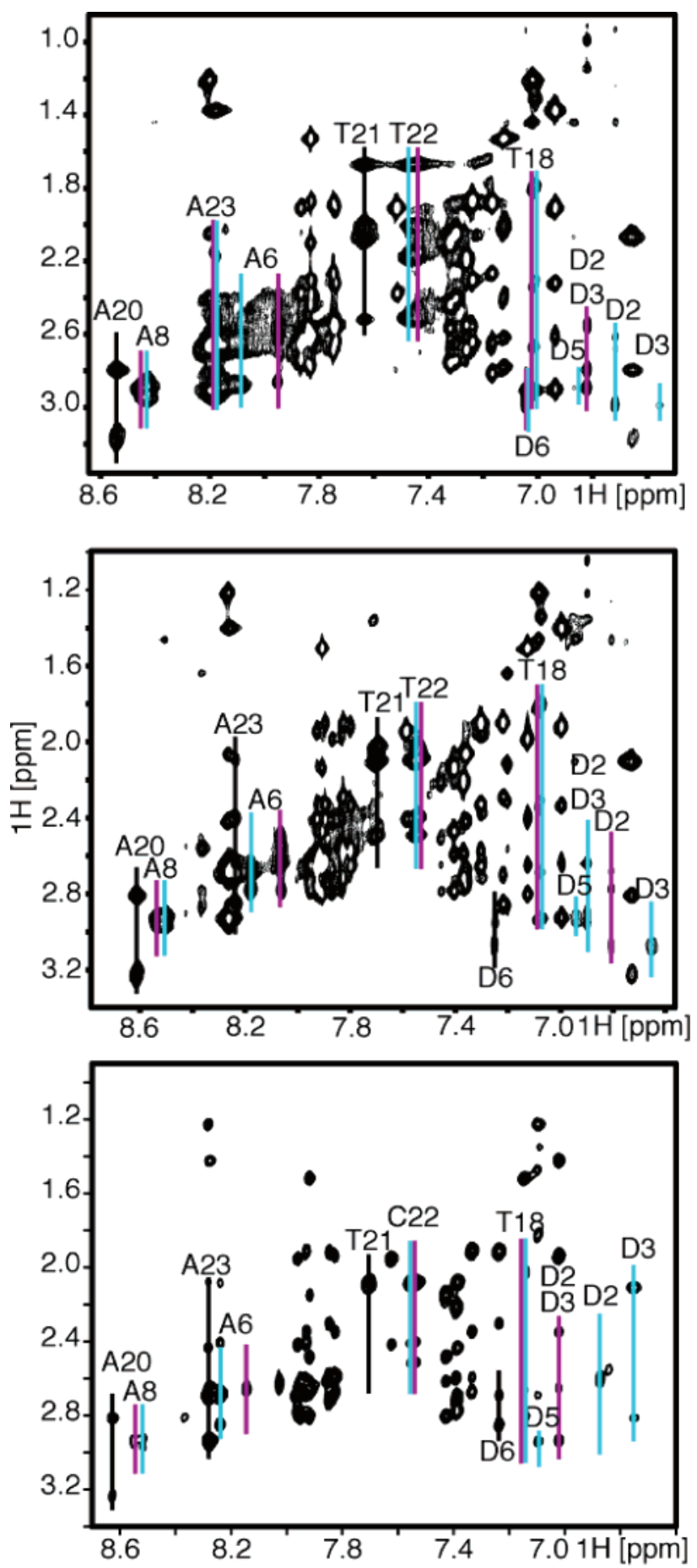

Figure 5. NOESY spectra of $5^{\prime}$-AAX (top), $5^{\prime}$-GAX (center), and 5'-ZAX (bottom).

Consequently, the question arises, to which extent the observed fluorescence lifetime of ${ }^{1}\left(\mathrm{X}^{+}\right)^{*}$ framed by $\mathrm{A} \cdot \mathrm{T}$ base pairs reflects a potential contribution from adenine oxidation as observed for other photooxidants. ${ }^{57,58}$ For the sequences in Table 1, this complication can be eliminated on the following grounds: On the basis of the quantum yield of $\Phi_{\mathrm{Fl}}=0.66$ and the lifetime of $19.2 \mathrm{~ns}$ of fluorescence, the upper limit for the radiative lifetime of $\mathrm{X}^{+}$is $\sim 30 \mathrm{~ns}$. This lifetime is in satisfying agreement with estimates of a radiative lifetime of $26 \mathrm{~ns}$ based on the Strickler-Berg approximation. ${ }^{59}$ Thus, the sequence $5^{\prime}$-AAX can be considered as an appropriate reference for the oxidation dynamics of $5^{\prime}$-ZAX and $5^{\prime}$-GAX, since adenine is not appreciably oxidized within the lifetime of ${ }^{1}\left(\mathrm{X}^{+}\right) * 60$ 


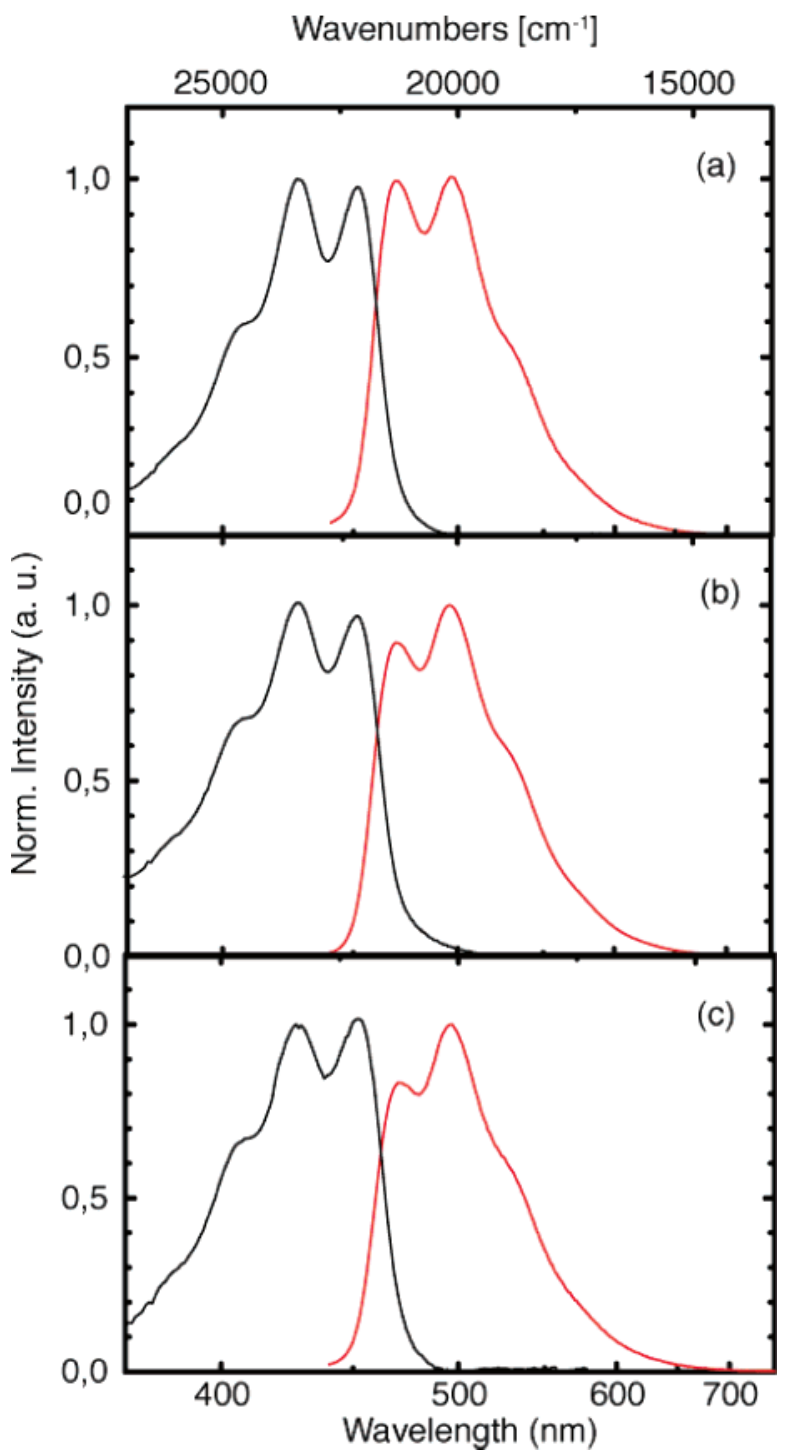

Figure 6. Absorption (black line) and fluorescence (red line, $\lambda_{\text {exc }}=$ $420 \mathrm{~nm})$ of $\mathrm{X}^{+}$-modified duplexes $(250 \mu \mathrm{M})$ in standard buffer at 273 $\mathrm{K}$ : (a) 5'-AAX; (b) 5'-GAX; (c) 5'-ZAX.

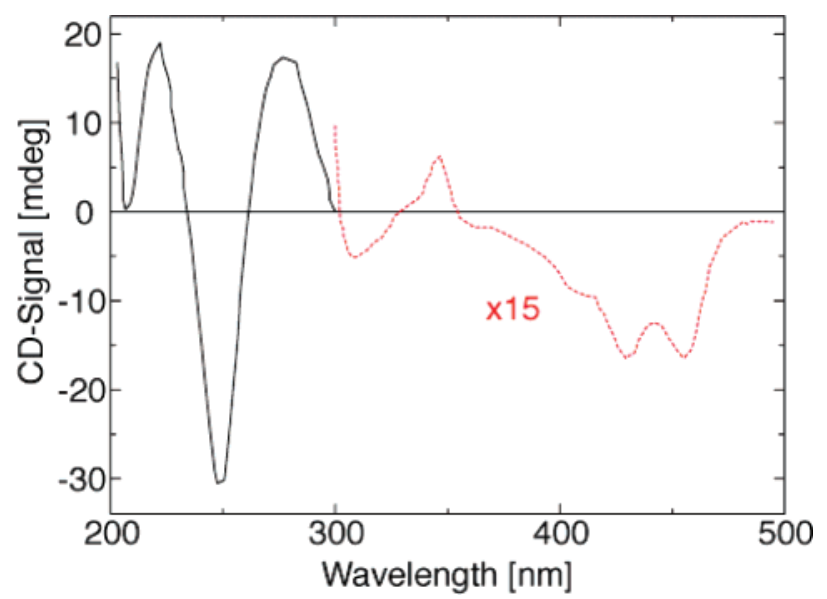

Figure 7. Circular dichroism spectrum of $5^{\prime}$-XAA. ${ }^{55}$

$5^{\prime}-G A^{l}\left(X^{+}\right)^{*}$. As compared to the long-lived monoexponential decay of the reference sequence $5^{\prime}$-AAX, the TCSPC fluorescence decay profile of $5^{\prime}$-GAX shows shorter lifetimes and a pronounced deviation from monoexponentiality. Fixing a third component of $19 \mathrm{~ns}$ with an amplitude of 5\% (reflecting a small population not undergoing charge shift), the fit yields $\tau_{1}=2.7$

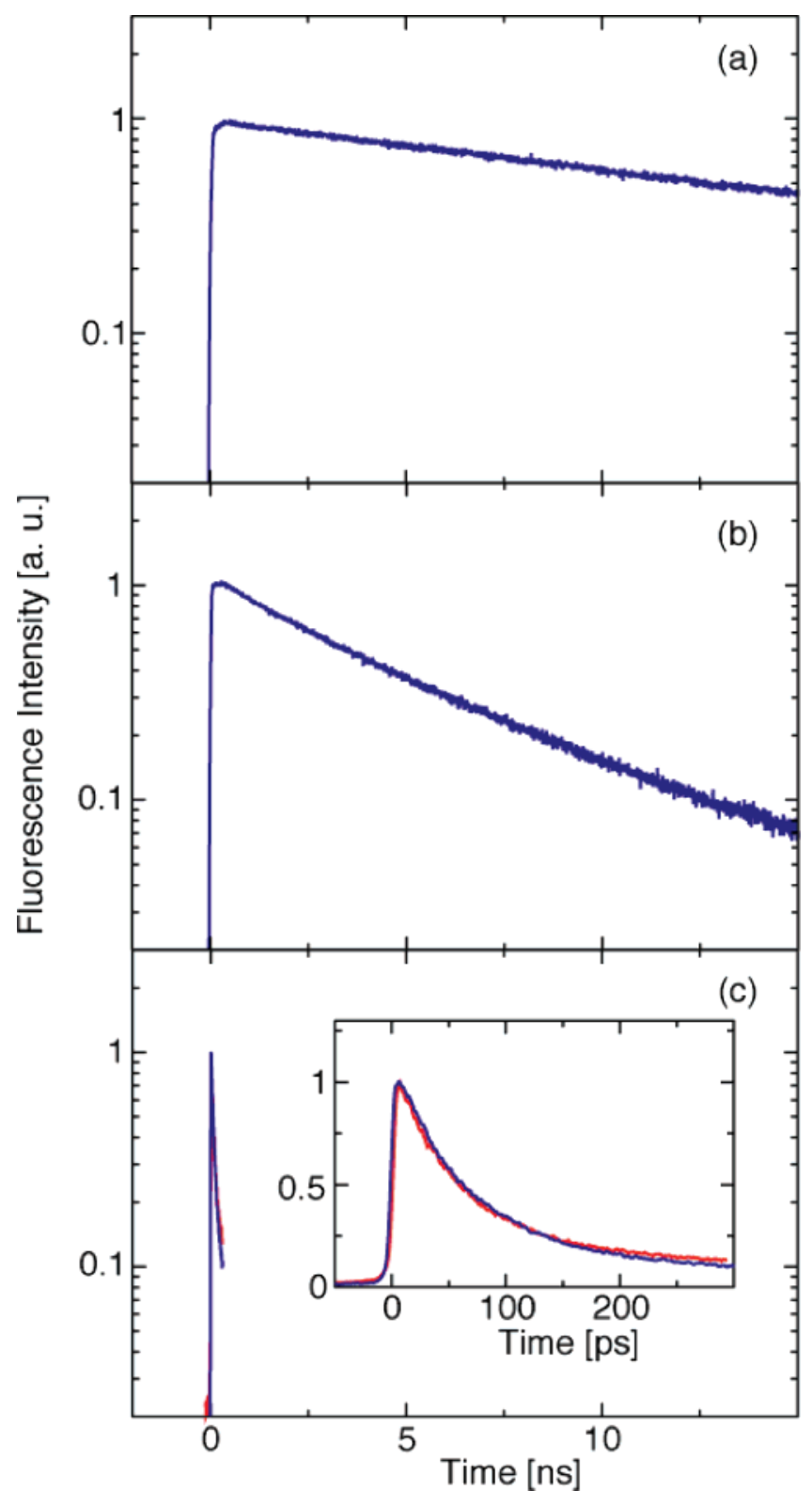

Figure 8. Fluorescence decay of 5'-AAX (a) and 5'-GAX (b) monitored by TCSPC at $470 \mathrm{~nm}(273 \mathrm{~K})$. Fluorescence decay of $5^{\prime}$-ZAX (c, blue) and $5^{\prime}$-ZAX $(\mathrm{c}$, red) monitored by streak camera at $510 \mathrm{~nm}(295 \mathrm{~K})$. Global fitting with fixed $19 \mathrm{~ns}(5 \%)$ for $5^{\prime}$-GAX and 5'-ZAX yields the following results: 5'-AAX, $\tau=19.2 \mathrm{~ns}(100 \%)$; $5^{\prime}$-GAX, $\tau_{1}=2.7 \mathrm{~ns}(52 \%)$ and $\tau_{2}=7.3 \mathrm{~ns}(48 \%) ; 5^{\prime}$-ZAX, $\tau_{1}=21$ ps $(33 \%)$ and $\tau_{2}=82 \mathrm{ps}(62 \%) .19 \mathrm{~ns}$ fixed, derived from $5^{\prime}$-AAX $(5 \%)$.

ns and $\tau_{2}=7.3 \mathrm{~ns}$ with similar amplitudes of the two components. ${ }^{61}$ Another key feature of $5^{\prime}-\mathrm{GAX}$ is that the recovery of the ground state absorption of the acridinium cannot be resolved. ${ }^{17 a}$ As a consequence, the formation of the $\mathrm{X}^{\bullet}$ radical is considered to be rate determining; that is, the radical decays faster than it is generated and a positive transient is not detectable.

$5^{\prime}-Z A^{l}\left(X^{+}\right) *$. In accordance with previous transient absorption experiments, ${ }^{17}$ the fluorescence of the easier to oxidize $5^{\prime}$-ZAX sequence decays on a much shorter time scale than the one of $5^{\prime}-\mathrm{GA}^{1}\left(\mathrm{X}^{+}\right) *$. Independent of the method applied (streak camera or upconversion techniques), the data could be fitted to two time constants: $\tau_{1}=20$ ps $(30 \%)$ and $\tau_{2}=80$ ps $(70 \%)$. The uncertainty of a single upconversion or streak camera experiment is about $\pm 10 \%$; the overall variance is slightly larger, that is, 


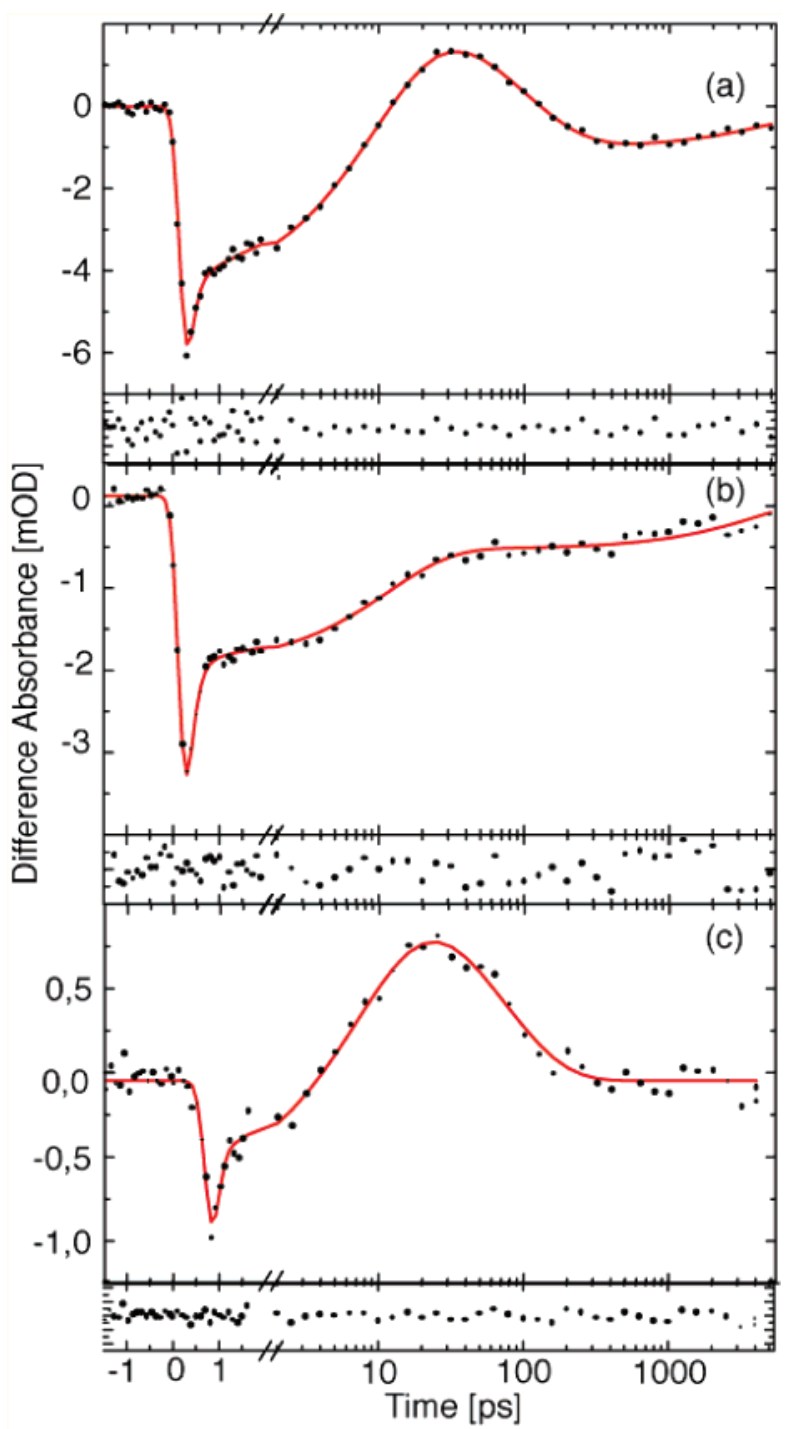

Figure 9. Time-resolved difference absorbance of 5'-ZAX (a), 5'-XAZ (b), and 5'-ZAXAZ (c) excited at $455 \mathrm{~nm}$ and monitored at $530 \mathrm{~nm}$ (273 K). The fit gives for $5^{\prime}$-ZAX 11 ps (-96\%), 63 ps (49\%), and 8.8 ns $(-4 \%)$; for $5^{\prime}$-XAZ 12 ps $(-69 \%)$, and $4.3 \mathrm{~ns}(-31 \%)$; and for $5^{\prime}$-ZAXAZ 8.3 ps $(-100 \%)$ and 70 ps $(72 \%)$.

about $\pm 15-20 \%$. In addition, a minor third component with a lifetime of $\tau_{3} \gg 4 \mathrm{~ns}$ and an amplitude of $<5 \%$ has been observed. Although the amplitude is very small, this subpopulation with lifetimes in the nanosecond range is predominantly responsible for the steady-state fluorescence spectrum (Figure 6c). Since this spectrum shows vibronic structure, we assume that this minority population of $\mathrm{X}^{+}$is still located in an organized environment. In this environment, the lifetime of the acridinium is considerably longer than the lifetime $\tau=3.5 \mathrm{~ns}$ of ${ }^{1}\left(\mathrm{X}^{+}\right)^{*}$ free in aqueous buffer in agreement with the literature. $^{47}$

In femtosecond absorption experiments (Figure 9a), the shorter of the two time constants measured in fluorescence shows up as the rise time of a positive signal to which the absorption of the radical product $\mathrm{X}^{\bullet}$ must be the predominant contribution. Such an assignment of the difference absorbance probed at $530 \mathrm{~nm}$ is also supported by the femtosecond/ picosecond difference absorbance spectra recorded between 360 and $660 \mathrm{~nm}$ (Supporting Information Figure S2.1). This positive difference absorption develops within 11 ps and decays on a time scale of 63 ps. On a similar time scale (83 ps) as this decay, the ground state population recovers, as shown in transient
TABLE 3: Compilation of Photoinduced Charge Shift Rates for $\mathrm{X}^{+} / \mathrm{DNA}$ Measured ${ }^{a}$

\begin{tabular}{lllllll}
\hline & $k_{1 \mathrm{~F}}\left(\mathrm{~s}^{-1}, \pm 10 \%\right)$ & $k_{1 \mathrm{~S}}\left(\mathrm{~s}^{-1}, \pm 10 \%\right)$ & $k_{2}\left(\mathrm{~s}^{-1}, \pm 10 \%\right)$ \\
\hline 5'-GAX & $3.3 \times 10^{8}$ & $b$ & $9.0 \times 10^{7}$ & $b$ & $\geq 4 \times 10^{8}$ & $c^{17}$ \\
5'-ZAX & $5.0 \times 10^{10}$ & $b$ & $1.3 \times 10^{10}$ & $b$ & & \\
& $9.1 \times 10^{10}$ & $c^{17}$ & & & $1.2 \times 10^{10}$ & $c^{17}$ \\
5'-XAZ & $8.3 \times 10^{10}$ & $c^{17}$ & $\ll 8 \times 10^{10}$ & $d$ & $5.9 \times 10^{9}$ & $c^{17}$ \\
5'-ZAXAZ & $1.2 \times 10^{11}$ & $c$ & & & $1.4 \times 10^{10}$ & $c$
\end{tabular}

${ }^{a}$ All rates correspond to $273 \mathrm{~K}$ with the exception of the fluorescence decay of 5'-ZAX measured at $295 \mathrm{~K}$. The nanosecond background signal of $<5 \%$ is omitted, since this minor component related to nonintercalated $\mathrm{X}^{+}$is irrelevant in the context of ET dynamics. ${ }^{b}$ ET rates from fluorescence decay, calculated according to $k_{\mathrm{ET}}=\tau_{\mathrm{FL}}{ }^{-1}-\tau_{0}{ }^{-1}$, where $\tau_{\mathrm{FL}}$ is the fluorescence decay time of ${ }^{1}\left(\mathrm{X}^{+}\right)^{*}$ and $\tau_{0}=19 \mathrm{~ns}$ is the lifetime of the reference $5^{\prime}$-AAX. ${ }^{c} \mathrm{ET}$ rates from transient absorption measurements not allowing the slow hole transfer rate corresponding to the long fluorescence component (see text) to be resolved. All values for $k_{2}$ refer to transient absorption experiments probed at $450 \mathrm{~nm}$, except for 5'-ZAXAZ probed at $530 \mathrm{~nm}$ (Figure 11). ${ }^{d}$ For 5 '-XAZ, only a limit on the slow component can be estimated from the low yield of $\mathrm{X}$ radicals.

absorption probed at the long-wavelength absorption maximum at $450 \mathrm{~nm} .{ }^{17}$ Moreover, this monoexponential recovery of the ground state coincides not only with the decay of the radical $\mathrm{X}^{\bullet}$ but also with the decay of the slow component $(80 \mathrm{ps})$ of the fluorescence. Thus, in transient absorption experiments, ${ }^{62}$ the decay of the positive difference absorption is due to the superposition of the decay of two species, the radical and the slow component of ${ }^{1}\left(\mathrm{X}^{+}\right)^{*}$.

When comparing the rates $\left(k_{1 \mathrm{~F}}\right)$ given in Table 3 for the sequence $5^{\prime}$-ZAX, it should be noticed that the fast rate $\left(k_{1 \mathrm{~F}}\right)$ measured in fluorescence is somewhat longer than the one measured in pump-probe experiments. This discrepancy is not understood. If it would be due to solvation/vibrational relaxation contributing more to the transient absorption signal than to decay of upconverted fluorescence as proposed for a similar phenomenon observed for DNA/RNA nucleotides and nucleosides, ${ }^{63}$ a fast phase should also show up in the reference sample $5^{\prime}$-AAX and this is not the case. ${ }^{17}$ Since the discrepancy of the rates $\left(k_{1 \mathrm{~F}}\right)$ corresponds to only about a factor of 2 , this uncertainty is not affecting the conclusions. In the following, we will base the discussion of the ET mechanism on the "worst" case, that is, the largest ratio of rates $k_{1 \mathrm{~F}}\left(5^{\prime}-\mathrm{ZAX}\right) / k_{1 \mathrm{~F}}\left(5^{\prime}-\mathrm{GAX}\right)=280$.

Role of Counterbase A20. In order to test the potential role of the adenine A20 in the complementary strand, this adenine has been replaced by a d-spacer which maintains the internucleotide phosphate distance (Chart 1). As illustrated in the streak camera experiments shown in Figure 8c, the fluorescence decay profiles of $5^{\prime}-\mathrm{ZAX}$ and $5^{\prime}-\mathrm{ZAX}_{\mathrm{d}}$ are identical, ruling out a significant influence of $\mathrm{A} 20$ on the lifetime profile of ${ }^{1}\left(\mathrm{X}^{+}\right)^{*}$.

Role of Directionality. The directionality of ${ }^{1}\left(\mathrm{X}^{+}\right)^{*}$ induced oxidation dynamics of $\mathrm{Z}$ has been studied in the sequence $5^{\prime}-1\left(X^{+}\right) * A Z$ where, in contrast with $5^{\prime}-Z A X$, the hole acceptor $\mathrm{Z}$ is now located at position 9 , the next-nearest neighbor position to $\mathrm{X}^{+}$in the $3^{\prime}$ direction. As shown in Figure 9b, the negative difference absorbance decays. However, it does not reach a positive value; that is, the amplitude of the radical contribution must be drastically reduced. The fit shows that the fastest component of the multiexponential decay is still $12 \mathrm{ps}$ and therefore similar to the one of $5^{\prime}$-ZAX. For all slower processes, the fit yields a nanosecond component with large amplitude. From the ground state recovery on a time scale of $170 \mathrm{ps},{ }^{16}$ we conclude that charge shift processes faster or close to this time constant take place and are not identified by the fit due to compensation of the temporal evolution of excited state and 
radical absorption and stimulated emission. On the basis of this argument, an assignment of the strong nanosecond component to $\mathrm{X}^{+}$not intercalated can be excluded.

Figure $9 \mathrm{c}$ shows the formation of the $\mathrm{X}^{\bullet}$ radical formation and its decay in the sequence $5^{\prime}-\mathrm{ZA}^{1}\left(\mathrm{X}^{+}\right) * \mathrm{AZ}$ with a symmetrical arrangement of $\mathrm{Z}$ at both next-nearest neighbor positions to $\mathrm{X}^{+}$. Here, the radical formation proceeds on the shorter time scale of 8 ps as compared to the fast components of 12 ps observed for both $5^{\prime}$-ZAX and $5^{\prime}$-XAZ. We note in passing that the amplitude of the nanosecond background signal is smaller than in both sequences $5^{\prime}$-ZAX and $5^{\prime}$-XAZ.

Summary. (i) In both $\mathrm{X}^{+}$/DNA systems 5'-GAX and 5'-ZAX, the decay of the excited state ${ }^{1}\left(\mathrm{X}^{+}\right)^{*}$ can be fitted to a biexponential function with comparable amplitudes. For the sequence 5'-ZAX where the two fluorescence components decay on the picosecond time scale ( $21 \mathrm{ps}, 82 \mathrm{ps})$, a minority signal $(<5 \%)$ with a long nanosecond lifetime ( $\gg 4 \mathrm{~ns}$ ) is observed in addition and taken into account in the fitting procedure. The return ET recovering the ground state follows monoexponential kinetics ( $83 \mathrm{ps)}$ and coincides with the slow component of the excited state decay ( $82 \mathrm{ps}$ ). (ii) The decay time of the fast fluorescence component of ${ }^{1}\left(\mathrm{X}^{+}\right)^{*}$ is independent of the direction of hole injection; however, this is not true for its amplitude. The relative amplitude of the fast component decreases significantly in favor of slow components when changing the direction from $5^{\prime}$-ZAX to $5^{\prime}$-XAZ. (iii) Replacement of adenine opposite to the chromophore $\mathrm{X}^{+}$by an abasic spacer does not influence the exited state dynamics of ${ }^{1}\left(\mathrm{X}^{+}\right)^{*}$. (iv) In $5^{\prime}$-GAX, the fast component of the injection reaction is by more than 2 orders of magnitude slower than that in $5^{\prime}$-ZAX. Since for none of the two fluorescence components the radical population is large enough to be detected in nanosecond absorption spectroscopy, the ground state recovery process related to both fluorescence components has to occur on a shorter time scale.

\section{Discussion}

The $\mathrm{X}^{+}$Binding Site. Hypochromicity of $\mathrm{X}^{+}$intercalated in the duplex as well as the induced CD spectrum on $\mathrm{X}^{+}$absorption indicate strong $\pi-\pi$ and dipolar interactions between $\mathrm{X}^{+}$and the flanking $\mathrm{A} \cdot \mathrm{T}$ base pairs. This view is detailed and quantified by the NMR structure, which reveals that more than $95 \%$ of the acridinium $\mathrm{X}^{+}$is stacked between the adjacent $\mathrm{A} \cdot \mathrm{T}$ base pairs A6•T21 and A8•T19 in a central, coplanar position with minimal twist and tilt angles $\left(<15^{\circ}\right)$ and that the methoxy substituent of $\mathrm{X}^{+}$shows a bimodal orientation either in the plane of the ring or at an angle of $70^{\circ}$ (Figure 4). Another important result of the present NMR structure (Figure 3 ) is the observation that the nucleobase A20 is clearly rotated away from the canonical position of a Watson-Crick double strand lacking any noticeable contacts with the duplex. This structural detail is in line with the observation that the oxidation dynamics of $5^{\prime}-\mathrm{ZAX}$ and $5^{\prime}-\mathrm{ZAX}_{\mathrm{d}}$ is not affected by the absence or presence of A20.

On the basis of HSQC spectra, only a small percentage $(<5 \%)$ of the $\mathrm{X}^{+}$/DNA complex is found in which the acridinium is outside the base stack, as this subpopulation is neither intercalated nor bound to grooves but still attached to the duplex by the $\mathrm{C}_{6}$-linker. Since binding to one of the sugars can also be excluded, in view of electrostatic interaction, the most probable site is one of the negatively charged phosphates. This minority also showing up in the picosecond fluorescence decay profile of $5^{\prime}$-ZAX as a small nanosecond background component is nevertheless responsible for its steady-state fluorescence spec- trum. The reduced vibronic structure as compared to $5^{\prime}-\mathrm{GAX}$ and the reference $5^{\prime}$-AAX is in accordance with the expectation that the non-intercalated subpopulation of $\mathrm{X}^{+}$is residing in a more inhomogeneous environment.

Assignment of Biexponential Fluorescence Decay of ${ }^{1}\left(\mathbf{X}^{+}\right) * / D N A$. A priori, the interpretation of biexponential fluorescence decay in a donor/acceptor system is not unique. In the simplest case, the two fluorescence components reflect one of two situations: (i) the presence of two conformers with different rate constants or, alternatively, (ii) a single conformation where on energetic grounds equilibrium between the initially excited state and the product state determines the excited state dynamics. As formally shown in Appendix B, the equilibrium model (ii) implies that, for both sequences $5^{\prime}$-ZAX and $5^{\prime}-\mathrm{GAX}$, a similar relative concentration of $\mathrm{X}^{\bullet}$ is observed, and this is not the case. In contrast to $5^{\prime}$-ZAX, the population of $\mathrm{X}^{\bullet}$ is too small to be detected in the case of $5^{\prime}$-GAX. Assuming that the origin of the biexponential fluorescence decay is the same in both sequences, we rule out the equilibrium model on the basis of this failure of internal consistency. Instead, we attribute the two fluorescence components in Table 3 to two conformers with different structures. In the kinetic scheme of Figure 10, we associate these with fast and slow ET rates denoted $k_{1 \mathrm{~F}}$ and $k_{1 \mathrm{~S}}$. In the following, we discuss the implications of the two time constants for the ET mechanism.

Hole Injection Kinetics. Fast Charge Shift Component. With the assumption that the structure of the two fast conformers in $5^{\prime}$-ZAX and $5^{\prime}$-GAX is similar, we correlate the fast rates $\left(k_{1 \mathrm{~F}}\right)$ of both sequences (Table 3, Figure 10) and ask the question of whether the (maximum) ratio of the fast rates $k_{1 \mathrm{~F}}\left(5^{\prime}-\mathrm{ZAX}\right) /$ $k_{1 \mathrm{~F}}\left(5^{\prime}-\mathrm{GAX}\right)=280$ can be explained by conventional ET theory (for formalism, see Appendix A). For this purpose, we make the following assumptions:

(1) The electronic couplings, $V\left(5^{\prime}-\mathrm{ZAX}\right)$ and $V\left(5^{\prime}-\mathrm{GAX}\right)$, responsible for ET from the purines $\mathrm{G}$ and $\mathrm{Z}$ to ${ }^{1}\left(\mathrm{X}^{+}\right)^{*}$ are similar. This assumption is supported by the almost identical structures derived from the NOESY spectra in Figure 5. Our quantum-chemical HF/6-31G* calculations based on a canonical B-structure predict for 5'-ZA and 5'-GA stacks similar hole transfer couplings, 0.130 and $0.127 \mathrm{eV}$, pointing also to similar geometries of the two sequences (Appendix C).

(2) Provided that assumption (1) holds, the two sequences 5 -GAX and 5'-ZAX differ predominantly in their donor/ acceptor energetics. Since similar reorganization energies $(\lambda)$ are expected for systems with identical donor/acceptor distances, we explore whether the different activation energies can be attributed to differences in the free energy change. The difference in driving force for oxidation of $\mathrm{G}$ and $\mathrm{Z}$ in $5^{\prime}$-GAX and $5^{\prime}-\mathrm{ZAX}$ is taken to be $\Delta G\left(5^{\prime}-\mathrm{GAX}\right)-\Delta G\left(5^{\prime}-\mathrm{ZAX}\right) \sim 0.3$ $\mathrm{eV}$. Such a value has been derived from irreversible oxidation potentials of the single nucleotides $\mathrm{dG}$ and $\mathrm{dZ}$ in solution. ${ }^{24} \mathrm{It}$ is larger than $\Delta G=-0.19 \pm 0.1 \mathrm{eV},{ }^{25}$ measured in situ, although in an indirect experiment, and similar to a value derived from kinetic modeling. ${ }^{10 \mathrm{c}}$ It is smaller than the difference -0.39 $\mathrm{eV}$ of ionization potentials of $\mathrm{G}$ and $\mathrm{Z}^{26}$ calculated for the gas phase. A more recent approach ${ }^{27}$ to the energetics of $\mathrm{G}$ and $\mathrm{Z}$ rests on quantum-chemical modeling of hole transfer through $\pi$ stacks. Also in this approach, the ionization potentials, and thus the energetics of hole transfer, are affected when purines are replaced by their 7-deaza analogues. The calculated driving force for hole transfer in the triplet $5^{\prime}$-AZT exceeds the one in 5'-AGT by $\sim 0.3 \mathrm{eV}$.

Assuming similar electronic couplings, $V\left(5^{\prime}-\mathrm{ZAX}\right)$ and $V(5-\mathrm{GAX})$, the ratio $k_{1 \mathrm{~F}}\left(5^{\prime}-\mathrm{ZAX}\right) / k_{1 \mathrm{~F}}\left(5^{\prime}-\mathrm{GAX}\right)$ is attributed to 


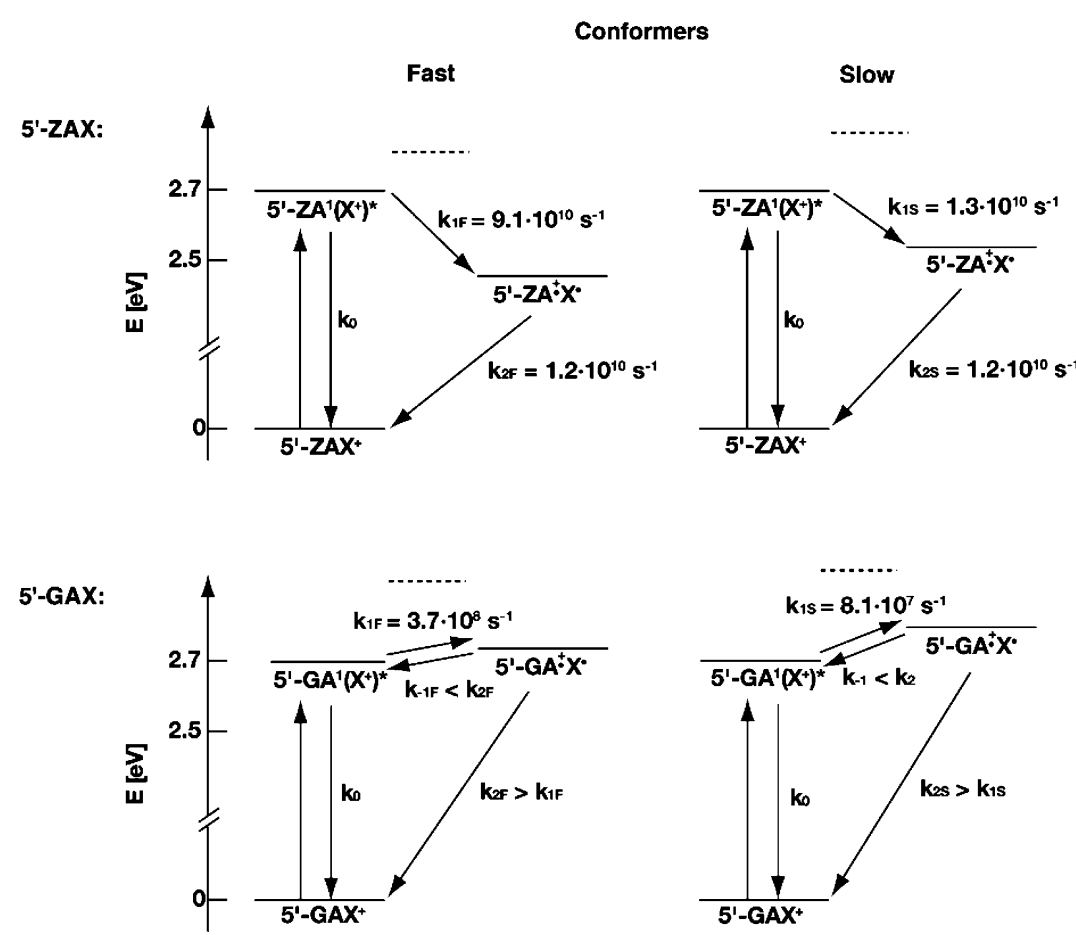

Figure 10. Kinetic schemes for $\mathrm{Z}$ and $\mathrm{G}$ oxidation in fast and slow conformations of the methoxy substituent of the acridinium in the sequences $5^{\prime}$-ZAX and 5'-GAX. All rates refer to $273 \mathrm{~K}$. The respective activation free energies are indicated by the dashed lines.

the Franck Condon factor and yields an increase of the activation free energy of $\Delta E_{\mathrm{a}}=0.13 \mathrm{eV}$ going from ZAX to GAX ${ }^{64} \mathrm{On}$ the basis of this activation free energy and the experimental value of the activation energy $E_{\mathrm{A}}\left(5^{\prime}-\mathrm{ZAX}\right)=0.09 \pm 0.1 \mathrm{eV}^{17 \mathrm{~b}}$ (assuming that the entropy of activation is zero), we obtain 0.22 $\mathrm{eV}$ for the activation free energy of $5^{\prime}$-GAX. For ET in the normal regime, classical Marcus theory ${ }^{28}$ (Appendix A) is a useful starting point, since quantum effects are expected to be small near room temperature. According to the relation for the activation free energy

$$
E_{\mathrm{a}}=(\lambda+\Delta G)^{2} / 4 \lambda
$$

and setting $\Delta G\left(5^{\prime}-\mathrm{ZAX}\right)-\Delta G\left(5^{\prime}-\mathrm{GAX}\right)=-0.3 \mathrm{eV}$, the respective activation free energies 0.09 and $0.22 \mathrm{eV}$ for $5^{\prime}$-ZAX and $5^{\prime}$-GAX would be consistent with similar reorganization energies $(\lambda)$ for the following free energy changes:

$$
\begin{aligned}
& \Delta G\left(5^{\prime}-\mathrm{ZAX}\right)=-0.25 \mathrm{eV} \text { corresponding to } \lambda\left(5^{\prime}-\mathrm{ZAX}\right)= \\
& 0.78 \pm 0.05 \mathrm{eV} \\
& \Delta G\left(5^{\prime}-\mathrm{GAX}\right)=+0.05 \mathrm{eV} \text { corresponding to } \lambda\left(5^{\prime}-\mathrm{GAX}\right)= \\
& 0.82 \pm 0.05 \mathrm{eV}
\end{aligned}
$$

These values for the driving force $(\Delta G)$ are underlying the tentative kinetic scheme in Figure 10. For increasingly negative $\Delta G$ values of $5^{\prime}$-GAX up to $-0.2 \mathrm{eV}$, similar reorganization energies for $5^{\prime}$-GAX and $5^{\prime}$-ZAX up to $1.15 \mathrm{eV}$ are still consistent with the experimental data. A smaller difference of the driving force comparing $5^{\prime}-\mathrm{GAX}$ and $5^{\prime}-\mathrm{ZAX}$, as, for example, the in situ experimental value of $\Delta(\Delta G)=0.19 \mathrm{eV},{ }^{25}$ would imply the reorganization energy for $5^{\prime}-\mathrm{GAX}$ is larger than that for $5^{\prime}$-ZAX.

In order to justify the attribution of the ratio of rates to the free energy change, we have to assess the contributions of the internal reorganization energies $\left(\lambda_{\text {int }}\right)$ of $\mathrm{G}$ and $\mathrm{Z}$ associated with changes of the intramolecular geometry of donor and acceptor brought about by their oxidation. To that goal, B3LYP/6-31G* calculations of the neutral states and radical cations of the $\mathrm{G} \cdot \mathrm{C}$ and $\mathrm{Z} \cdot \mathrm{C}$ base pairs have been performed (Appendix $\mathrm{C}$ ). Although the electron density distribution in $\mathrm{G}$ and $\mathrm{Z}$ is found to be quite different, the internal reorganization energies for oxidation of $\mathrm{G}$ and $\mathrm{Z}$ turn out to be similar, 8.14 and 8.23 $\mathrm{kcal} / \mathrm{mol}$. However, there may be a caveat, since this similarity of the internal reorganization energies might be weakened due to hydrogen bond formation at the N7 position of guanine involving water. Such hydrogen bond interaction would favor a larger reorganization term for $5^{\prime}-\mathrm{GAX}$ as compared to $5^{\prime}$-ZAX where due to the replacement of $\mathrm{N} 7$ by $\mathrm{CH}$ such hydrogen bond formation is not possible.

Slow Charge Shift Component and Ground State Return. An important feature of the slow kinetic components in both $5^{\prime}$-ZAX and 5'-GAX is the observation that these are depending on the oxidation potential of the purine base. On this basis, we attribute also the slow fluorescence components in both systems to the oxidation of $\mathrm{G}$ or $\mathrm{Z}$. It is characteristic for the slow rate $\left(k_{1 S}\right)$ in $5^{\prime}$-ZAX that the respective ground state return $\left(k_{2}\right)$ is masked by the slow rate of forward charge shift $\left(k_{1 \mathrm{~s}}\right)$, which is more thermally activated than the fast rate $\left(k_{1 \mathrm{~F}}\right)$. Assuming again similar couplings for the two $5^{\prime}$-ZAX conformers underlying the two rate constants $\left(k_{1 \mathrm{~F}}\right.$ and $\left.k_{1 \mathrm{~S}}\right)$, the activation free energy of the slow forward charge shift component $\left(k_{1 \mathrm{~S}}\right)$ would exceed the one of the fast rate $\left(k_{1 \mathrm{~F}}\right)$ by $0.04-0.05 \mathrm{eV}$. The activation energy of $E_{\mathrm{a}}=0.13 \mathrm{eV}^{17 \mathrm{~b}}$ measured for the combined decay of the "slow" $1\left(\mathrm{X}^{+}\right) *$ component and the $\mathrm{X} \cdot$ radical formed by the "fast" conformer is then dominated by the activation energy of the slow component $\left(k_{1 S}\right)$. This picture removes the problem related to the "apparent" large activation energy of the ET in the inverted regime, as pointed out in the Introduction. On the basis of the $\mathrm{S}_{0}-\mathrm{S}_{1}$ excitation energy of $2.7 \mathrm{eV}$ and independent of the exact value of the forward driving force, the free energy gap of $k_{2}$ is of the order of $2.4 \mathrm{eV}$ or larger. Then, the ground state return rates $\left(k_{2}\right)$ of the fast and slow subpopulation are expected to be similar $\left(1.2 \times 10^{10} \mathrm{~s}^{-1}\right)$. 
An analogous argument applies to the interpretation of the two fluorescence components of 5'-GAX. As in 5'-ZAX, also here the rate $k_{2}$ is deeply in the inverted regime and the ground state return rates of both conformers in 5'-GAX are expected to be similar to the ones of $5^{\prime}$-ZAX. Therefore, in view of the forward charge shift with its higher activation energy as compared to $5^{\prime}-\mathrm{ZAX}$, it is not surprising that the back transfer rate $\left(k_{2}\right)$ is not resolvable for any of the two components. Assuming also similar electronic couplings for the two 5'-GAX conformers, the difference between fast and slow rates would be equivalent to an increase of activation free energy for the slow rate of $0.03-0.04 \mathrm{eV}$. The finding that the ratio of rates in $5^{\prime}$-GAX is smaller than that in $5^{\prime}$-ZAX by $30 \%$ points to the limit of the underlying assumptions.

Biexponential Fluorescence and Bimodal Conformations of the Acridinium's Methoxy Group. The role of the methoxy group in cis - trans isomerization applied to biexponential fluorescence of the acridinium $\mathrm{X}^{+}$in aqueous solution has been discussed before. ${ }^{47,65}$ This concept is supported by quantum-chemical calculations in the gas phase providing an activation barrier of $0.23 \mathrm{eV}^{66}$ Extension of these calculations to an aqueous environment points to an energy loss of $0.065 \mathrm{eV} .{ }^{67}$ In the context of the NMR structure of the acridinium presented in this paper, the effect of the methoxy group rotation on the oxidation potential of $\mathrm{X}^{+}$has been studied using the semiempirical INDO/S method considering several conformations of the methoxy group with respect to the ring plane of the acridinium (Appendix C). It was found that indeed the rotation of $-\mathrm{OCH}_{3}$ affects the energy of the donor $\mathrm{X}^{+}$without influencing the electronic couplings of $\mathrm{X}^{+}$and the acceptor state. When going from the planar structure of $\mathrm{X}^{+}$to a structure with an out-of-plane methoxy group, the free energy change for ET becomes more negative by $0.054 \mathrm{eV}$ (at a twist angle of $45^{\circ}$ ) and by $0.168 \mathrm{eV}$ in the perpendicular conformation. Since $\mathrm{X}^{+}$ is a stronger oxidant when the methoxy group is in a nonplanar position, we associate this conformation with the fast component of the biexponential fluorescence decay pattern of ${ }^{1}\left(\mathrm{X}^{+}\right)^{*}$ and the planar conformation with the slow component. In view of the bimodal structure of $\mathrm{X}^{+}$in the DNA duplex, dedicated studies on spectral changes in the different time domains due to the prevalence of one or the other conformer are in progress.

Directionality of Hole Injection. One of the unexplained phenomena $^{17}$ is the dependence of hole injection kinetics on the directionality of the base stack. In fact, the NMR studies of this paper revealed that the degree of $\pi$ stack disorder in the vicinity of $\mathrm{X}^{+}$is larger in the $5^{\prime}-3^{\prime}$ direction than in the $3^{\prime}-5^{\prime}$ direction. The NMR structure based on line width analysis (Supporting Information Figure S1.3) reveals that the base proton resonances in the $\mathrm{X}^{+}$-labeled strand are broader toward the $3^{\prime}$ end as compared to the $5^{\prime}$ end, showing a maximum at position 9 . This points to a structural inhomogeneity that is averaged on a millisecond to microsecond time scale. If one or several of the conformations display a slow hole transfer rate, deviations of the rate from monoexponentiality would be expected, as described in section 4 . The observed increase of structural inhomogeneity in the $5^{\prime}-3^{\prime}$ direction should lead to a directional dependence of the hole transfer rates, in the simplest case just due to differences in the electronic couplings.

The self-consistency of the kinetic data (Figure 9) obtained for the systems $5^{\prime}$-ZAX and $5^{\prime}$-XAZ is emphasized by the excited state dynamics of the symmetrical system $5^{\prime}$-ZAXAZ, where the triplet tract AXA is framed by the two electron donors Z. In this case, the radical pair is formed with a time constant of $8 \mathrm{ps}$, which is significantly shorter than both short time constants, 11 and $12 \mathrm{ps}$, for the unidirectional hole transfer in either $5^{\prime}$-ZAX or $5^{\prime}$-XAZ. The shorter time constant of $8 \mathrm{ps}$ is consistent with a smaller fraction of maximal $25 \%$ undergoing fast hole transfer in $5^{\prime}$-XAZ as compared to maximal $50 \%$ to the other direction as in $5^{\prime}$-ZAX. This upper limit of $25 \%$ for the fast hole transfer in the $5^{\prime}-3^{\prime}$ direction confirms independently the discussion of the hole transfer in $5^{\prime}$-XAZ given above.

Although this phenomenology of directional hole transfer in DNA in a system showing a directional dependence of structural distortions cannot be compared to the behavior of an ideal DNA duplex, it is worthwhile to consider the results from recent quantum-chemical calculations ${ }^{68}$ for unperturbed B-DNA, whereas in the present experiments-the acridinium $\mathrm{X}^{+}$occupies the site of an internal $\mathrm{A} \cdot \mathrm{T}$ base pair. As these calculations show, the electronic couplings responsible for hole injection depend strongly on the rotation of the intercalated acridinium within the helical DNA stack. Thus, the directionality of charge injection by any intercalator is not a universal feature of the DNA duplex but depends critically on the twist angle which determines the rotation of the molecular plane of the intercalator with respect to the central DNA axis. As predicted, ${ }^{68}$ besides conformations with strong directionality where the excess charge is preferentially transferred in either one of the two directions of the helix, there is a large subspace of twist angles where ET rates in both directions are comparable. Apparently, in the complexes 5'-ZAX, 5'-XAZ, and 5'-ZAXAZ, the arrangement of $X$ within the stack corresponds to a conformation with weak directionality of charge injection and it is the increased disorder in the 5'-3' direction which leads to an increase of the amplitudes of slow hole ET transfer rates without suppressing the fast processes in totality.

\section{Concluding Remarks}

We studied in this paper the oxidation dynamics of guanine $(\mathrm{G})$ and 7-deazaguanine $(\mathrm{Z})$ in the DNA double strands. In a central position of a $13 \mathrm{mer}$, a thymine is replaced by an acridinium derivative $X$ tethered to the backbone and separated from $\mathrm{G}$ and $\mathrm{Z}$ by one $\mathrm{A} \cdot \mathrm{T}$ base pair. Femtosecond/nanosecond time-resolved absorption and fluorescence spectroscopy shows that classical Marcus theory can explain the difference of more than 2 orders of magnitude between charge shift rates in $5^{\prime}$ ZAX and 5'-GAX on the basis of the Franck-Condon factor alone, and, since the reorganization energies can be assumed to be similar, on the basis of the free energy difference. The NMR structures and quantum-chemical calculations justify the neglect of differences in the donor/acceptor electronic couplings.

The extension of previous femtosecond/picosecond absorption studies ${ }^{17}$ to fluorescence measurements allows two conformations of the protonated acridinium acceptor $\mathrm{X}^{+}$(9-alkylamino6-chloro-2-methoxyacridinium) to be identified that differ in energetics rather than in the electronic couplings. This new information allows assignment problems related to femtosecond absorption data to be removed and the dynamics of hole injection to be treated self-consistently within conventional ET theory.

Apart from putting the applicability of conventional ET theory to test on the acridinium-modifed DNA duplex, the primary intention of this paper was directed toward a deeper understanding of the charge injection process using an approach that combines NMR structural analysis, time-resolved spectroscopy, and quantum-chemical calculations. The key results are summarized as follows:

(i) In more than $95 \%$ of the duplexes, the acridinium $\mathrm{X}^{+}$is located in a central, coplanar position between $\mathrm{A} \cdot \mathrm{T}$ base pairs 
with its long axis in parallel showing minimal twist and tilt angles $\left(<15^{\circ}\right)$. The complementary adenine base is turned out into the extrahelical space, without affecting the ET dynamics. In a minority of less than $5 \%$, the acridinium $\mathrm{X}^{+}$is found to be still attached to the duplex but not intercalated within the base stack. It is most probably associated with one of the nearby phosphates, since it is neither intercalated between remote base pairs nor bound to sugars or to the major or minor grooves. In transient absorption and fluorescence experiments, this minority leads to a small background signal with a long excited state lifetime (>5 ns).

(ii) Although the intercalation mode of the acridinium is well defined, the NMR structure reveals that there are two conformations of $\mathrm{X}^{+}$with respect to the arrangement of the methoxy substituent. In one conformation, the methoxy group is in the plane of the chromophore, while, in the other extraplanar conformation, the methoxy group forms a torsional angle of $70^{\circ}$ with the acridinium ring. The fluorescence decay of $5^{\prime}$ ZAX and 5'-GAX can be fitted to a biexponential function with similar amplitudes, reflecting the oxidation dynamics of $G$ and $\mathrm{Z}$, with the slower rate being predominantly determined by larger thermal activation energy. The attribution of biexponential ET dynamics to the bimodal orientation of the methoxy group at the acridinium is supported by quantum-chemical calculations which predict a larger free energy change for the hole transfer for the nonplanar conformation as compared to the planar one, whereas the difference in the donor/acceptor electronic couplings is negligible.

(iii) Kinetic studies on the directionality of the ${ }^{1}\left(\mathrm{X}^{+}\right) *$ induced hole injection reveal similarly fast decay components in $5^{\prime}$-ZAX and $5^{\prime}-X A Z$, although their amplitude is significantly reduced in $5^{\prime}$-XAZ. The NMR structure shows that this feature reflects local structural deviations from B-DNA which are much more pronounced in the $3^{\prime}-5^{\prime}$ direction than in the $5^{\prime}-3^{\prime}$ direction. According to recent quantum-chemical calculations, ${ }^{68}$ the directionality of hole injection is not a universal feature of the DNA duplex but depends critically on the rotation angle of the aromatic plane of the intercalator within the $\pi$ stack. The arrangement of $\mathrm{X}^{+}$in $5^{\prime}$-ZAX and $5^{\prime}$-XAZ corresponds to a conformation with weak directionality of the electronic couplings, with the increased disorder in the $3^{\prime}-5^{\prime}$ direction favoring slow hole transfer processes at the expense of fast ones. The structural heterogeneity in the $3^{\prime}-5^{\prime}$ direction is corroborated by larger line widths of the proton resonances in this direction, indicating exchange between conformations on the milli- to microsecond time scale which is static when compared to the time scale of hole injection.

As the driving force for hole shift from ${ }^{1}\left(\mathrm{X}^{+}\right)^{*}$ to guanine in $5^{\prime}$-GAX is shown to be close to zero, the activation free energy of $\sim 0.2 \mathrm{eV}$ is responsible for a relatively small ET rate of the order of $10^{8} \mathrm{~s}^{-1}$, consistent with a donor/acceptor electronic coupling of $60 \mathrm{~cm}^{-1}$. As the energetics for ET in $5^{\prime}$-GAX resembles the one for hole hopping along GAG tracts in the unperturbed duplex, it might of interest that similar rates of hole hopping along the base stack have been extracted ${ }^{69}$ from Giese experiments. ${ }^{11}$ This coincidence of hole-shift rates with zero driving force may point to a similar role of nuclear base dynamics in hole hopping between nucleobases in AGAGA tracts and in single-step guanine oxidation by intercalated acridinium $\mathrm{X}^{+}$in AGAXA sequences. Despite the attractive concept of conformational gating of ET in floppy DNA strands, there is no need in the acridinium/DNA system to envoke fluctuations of the electronic couplings that permit the electron transfer to occur.
Acknowledgment. We are highly indebted to O. Schiemann and J. Ulstrup for critically reading the manuscript and a lot of constructive remarks. Our warm thanks go also to R. A. Marcus and M. D. Newton for invaluable suggestions and many discussions on the subject of this paper over the years. The research was funded by the European Commission within The Sixth Framework Programme (Priority NMP): CiDNA (NMP4CT-2003-505669). C.G. was supported by the Max Planck Society and the Fonds der Chemischen Industrie.

\section{Appendix A}

Application of ET Theory to the $\mathrm{X}^{+}$/DNA Donor/Acceptor System. According to Marcus-Levich-Jortner theory, ${ }^{71,72}$ the rate for non-adiabatic ET is given by

$$
k_{\mathrm{E}} T=\frac{2 \pi}{\hbar} V^{2} F C
$$

where $V$ is the electronic coupling and FC is the thermally averaged vibrational overlap nuclear Franck-Condon factor. In the classical limit, that is, when $\bar{\omega}_{\mathrm{m}} \ll k_{\mathrm{B}} T$, where $\omega_{\mathrm{m}}$ is the characteristic frequency of medium modes, FC can be expressed as

$$
\mathrm{FC}=\frac{1}{\sqrt{4 \pi \lambda k_{\mathrm{B}} T}} \exp \left(-\frac{E_{\mathrm{a}}}{k_{\mathrm{B}} T}\right)
$$

with the activation free energy denoted by $E_{\mathrm{a}}$

$$
E_{\mathrm{a}}=\frac{(\Delta G+\lambda)^{2}}{4 \lambda}
$$

$\lambda$ is the reorganization energy containing contributions from polarization changes in the dielectric environment (medium reorganization energy $\lambda_{\mathrm{s}}$ ) and from the vibrations of the molecules (intramolecular $\lambda_{\mathrm{v}}$ ). $\Delta G$ is the free energy change of the reaction.

Equation 1 advances a universal classification of ET reactions to normal $(-\Delta G<\lambda)$, activationless $(-\Delta G=\lambda)$, and inverted $(-\Delta G>\lambda)$ regions. Importantly, the ET rate should decrease strongly with increasing driving force for exergonic reactions. In order to account for ET experiments showing only a weak decrease of the ET rate in the inverted region, the classical Marcus theory was extended to incorporate simultaneous contributions of low-frequency classical medium modes and of high-frequency quantum modes. The FC factor was modified to the form ${ }^{18,71}$

$\mathrm{FC}=\frac{1}{\sqrt{4 \pi \lambda_{\mathrm{s}} k_{\mathrm{B}} T}} \mathrm{e}^{-S_{\mathrm{c}}} \sum_{n=0}^{\infty} \frac{\left(S_{\mathrm{c}}\right)^{n}}{n !} \exp \left(-\frac{\left(\Delta G+n \hbar \omega+\lambda_{\mathrm{s}}\right)^{2}}{4 \lambda_{\mathrm{s}} k_{\mathrm{B}} T}\right)$

Here, the high-frequency quantum modes are represented by a single (average) vibrational mode $(\omega)$ with $\hbar \omega \gg k_{\mathrm{B}} T$ with a coupling strength of $S_{\mathrm{c}}=\lambda_{\mathrm{v}} / \hbar \omega$. The high-frequency intramolecular vibrational excitations of the donor and acceptor species provide a multitude of parallel ET channels. Vibrational excitations of these modes of the reaction products induced by ET in the inverted regime reduce the effective free energy gap and, thus, the activation energy of the rate.

Using eq 2, the contribution of $\lambda_{\mathrm{v}}$ to the observed overall reorganization energy can be estimated. Employing the customary vibrational frequency of $1500 \mathrm{~cm}^{-1}$ (a typical skeletal vibration of an aromatic compound), $\lambda_{\mathrm{v}}$ values range from 0.1 


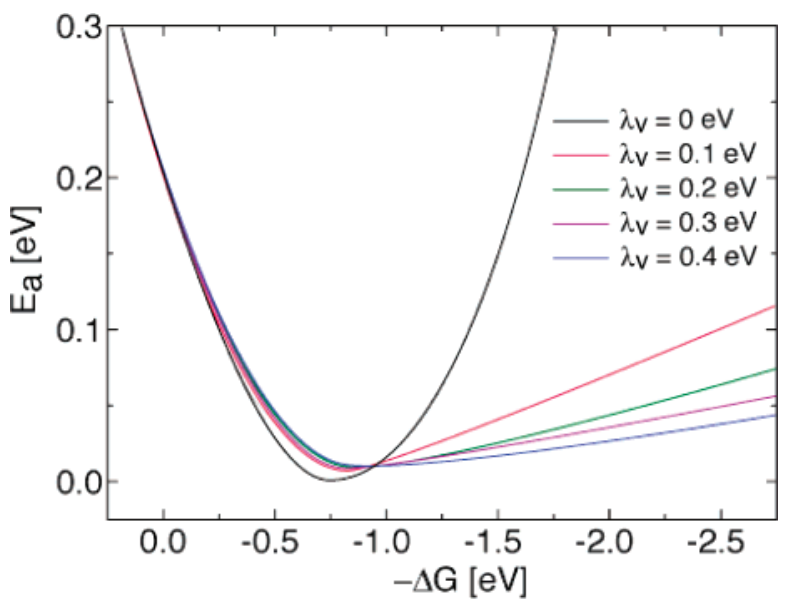

Figure 11. Activation free energies for $\mathrm{Z}$ oxidation in $5^{\prime}$-ZAX with different contributions from the vibrational reorganization energy $\left(\lambda_{\mathrm{v}}\right) .^{55}$ The activation free energies were calculated according to the semiclassical model using $\lambda_{\mathrm{s}}=0.8 \mathrm{eV}$ and $\omega_{\mathrm{s}}=1500 \mathrm{~cm}^{-1}$.

to $0.4 \mathrm{eV}$. The high-frequency modes principally affect the inverted regime, but even in the normal region, some degree of nuclear tunneling associated with the high-frequency modes can be expected to lower the activation energy relative to the classical limit. As a result of this tunneling, the quantity $\lambda$ in eq 2 may be viewed as an effective $\lambda_{\text {eff }}$ value corresponding to the sum of $\lambda_{\mathrm{s}}$ and some fraction of $\lambda_{\mathrm{v}}$, expressed with a fractional coefficient, $\alpha$ :

$$
\lambda_{\text {eff }}=\lambda_{\mathrm{s}}+\alpha \lambda_{\mathrm{v}}
$$

$\lambda_{\text {eff }}$ can be understood as the reorganization energy in the classical Marcus expression (eq 1) reproducing the semiclassical activation energies. For donor/acceptor systems in the normal regime, such as $5^{\prime}$-ZAX and 5'-GAX, $\alpha$ values of only $\sim 5-20 \%$ are required to obtain equivalence between the semiclassical $E_{\mathrm{a}}$ values and their classical counterparts. Thus, the $\lambda$ estimates of these systems are expected to be dominated by $\lambda_{\mathrm{s}}$.

Figure 11 shows the semiclassical activation energies calculated for $\lambda_{\mathrm{s}}=0.8 \mathrm{eV}$, the experimental value for $5^{\prime}-\mathrm{ZAX},{ }^{17}$ and varying vibrational reorganization energies. Clearly, quantum effects are small in the normal region. However, the contribution of the vibrational modes is essential in the inverted regime, that is, for the backward hole shift, and should lead to rates with very small activation energies. An estimate for the vibrational contribution to the total reorganization energy can also be obtained by globally applying semiclassical ET theory to the forward and backward hole transfer rates. Using the published values ${ }^{17}$ for the forward and ground state return rates in $5^{\prime}$-ZAX together with the estimate for the medium reorganization energy, $\lambda_{\mathrm{s}}=0.7-0.8 \mathrm{eV}$, a variation of the driving force in the range $\Delta G=-(0.4-0.6) \mathrm{eV}$ yields $\lambda_{\mathrm{v}}$ values in the range $0.3-0.4 \mathrm{eV}$. For these values of $\lambda_{\mathrm{s}}$ and $\lambda_{\mathrm{v}}$ and a driving force $\geq 2.3 \mathrm{eV}$ for the ground state return $\mathrm{ET} \mathrm{X}^{\bullet} \mathrm{A}\left(\mathrm{Z}^{+}\right)^{\bullet} \rightarrow$ $\mathrm{X}^{+} \mathrm{AZ}$, the semiempirical model predicts $E_{\mathrm{a}}<0.05 \mathrm{eV}$, as illustrated in Figure 11. Since this estimate is much smaller than the measured value of $E_{\mathrm{a}}=0.13 \mathrm{eV},{ }^{17 \mathrm{~b}}$ this discrepancy asks for reexamination.

However, it should be kept in mind that, for instance, changes in bridge energetics may mask the predictions for the Marcus inverted regime and may result in thermally activated, conformational gating of the ET process. In fact, such an "anomaly" in terms of inverted regime behavior has been reported for an artificial donor-bridge-acceptor system. ${ }^{72}$

\section{Appendix B}

Equilibrium between ${ }^{1}\left(\mathbf{X}^{+}\right)^{*}$ and $\mathbf{X}^{\bullet}$. In the case that the driving force of ET is close to zero and charge injection with rate $k_{1}$ is almost isoenergetic, the excited state can be repopulated from the radical pair state by a reverse process $\left(k_{-1}\right)$. In such a situation, biexponential fluorescence kinetics reflects the establishment $\left(\tau_{1}\right)$ and the decay $\left(\tau_{2}\right)$ of the equilibrium between the excited state and radical pair. As realized previously for donor/ acceptor cyclophanes in solution, the rates $k_{1}, k_{-1}$, and $k_{2}$ (return ET to the ground state) can be calculated from the fluorescence decay profile using the formalism applied previously to photoinduced ET in donor/acceptor cyclophanes: ${ }^{73}$

$$
I(t)=A_{1} \exp \left(-t / \tau_{1}\right)+\left(1-A_{1}\right) \exp \left(-t / \tau_{2}\right)
$$

The fluorescence lifetimes $\left(\tau_{0}\right)$ according to the following set of equations are

$$
\begin{gathered}
\tau_{1}=2\left(k_{0}+k_{1}+k_{2}+k_{-1}+\right. \\
\left.\sqrt{\left.\left(k_{0}+k_{1}-k_{2}-k_{-1}\right)^{2}+4 k_{1} k_{-1}\right)}\right)^{-1} \\
\tau_{2}=2\left(k_{0}+k_{1}+k_{2}+k_{-1}-\right. \\
\left.\sqrt{\left(k_{0}+k_{1}-k_{2}-k_{-1}\right)^{2}+4 k_{1} k_{-1}}\right)^{-1} \\
A_{1}=\frac{k_{0}+k_{2}-\tau_{2}^{-1}}{\tau_{1}^{-1}-\tau_{2}^{-1}}
\end{gathered}
$$

Applying these equations to the two fluorescence components of 5'-ZAX, 20 ps (33\%) and 90 ps $(66 \%)$, yields the following ET rates.

$$
k_{1}=(41 \mathrm{ps})^{-1} ; k_{-1}=(86 \mathrm{ps})^{-1} ; k_{2}=(42 \mathrm{ps})^{-1}
$$

A numerical simulation of the temporal evolution of the relevant states, the excited state ${ }^{1}\left(\mathrm{X}^{+}\right)^{*}$, the radical pair state $\mathrm{X}^{\bullet} \mathrm{A}\left(\mathrm{Z}^{+}\right)^{\bullet}$, and the ground state $5^{\prime}-\mathrm{ZAX}^{+}$, is shown in Figure $12 \mathrm{~d}$. The maximal relative population of the radical pair state is about $30 \%$. The results are in almost perfect agreement with the transient absorption data of 5'-ZAX for radical pair formation (Figure 12c) and return transfer recovering the ground state. ${ }^{17 \mathrm{a}}$ In case this model holds, the driving force for $\mathrm{Z}$ oxidation by ${ }^{1}\left(\mathrm{X}^{+}\right) *$ would be smaller than $k_{\mathrm{B}} T$.

However, the main obstacle to the validity of the equilibrium model results from the application of the same analysis to the biexponential fluorescence decay profile of 5'-GAX. Fluorescence decay components of 2.7 and 7.4 ns with equal amplitudes are represented by an almost identical kinetic scheme, though on a time scale longer by a factor of 100 yielding rates of

$$
k_{1}=(5.0 \mathrm{~ns})^{-1} ; k_{-1}=(15 \mathrm{~ns})^{-1} ; k_{2}=(5.4 \mathrm{~ns})^{-1}
$$

Consequently, the numerical simulation also predicts a maximal relative population of the radical pair state of $30 \%$. However, this radical population is not observed (Figure 12a). In addition, also for 5'-GAX, the model implies a driving force in the order of $k_{\mathrm{B}} T$, so that the ratio of ET rates $>100$ has to be assigned to large differences in electronic couplings. NMR structural data do not indicate such a drastic change.

\section{Appendix C}

Computational Details. Recently, CASSCF and CASPT2 calculations of the energetics and electronic couplings for hole 


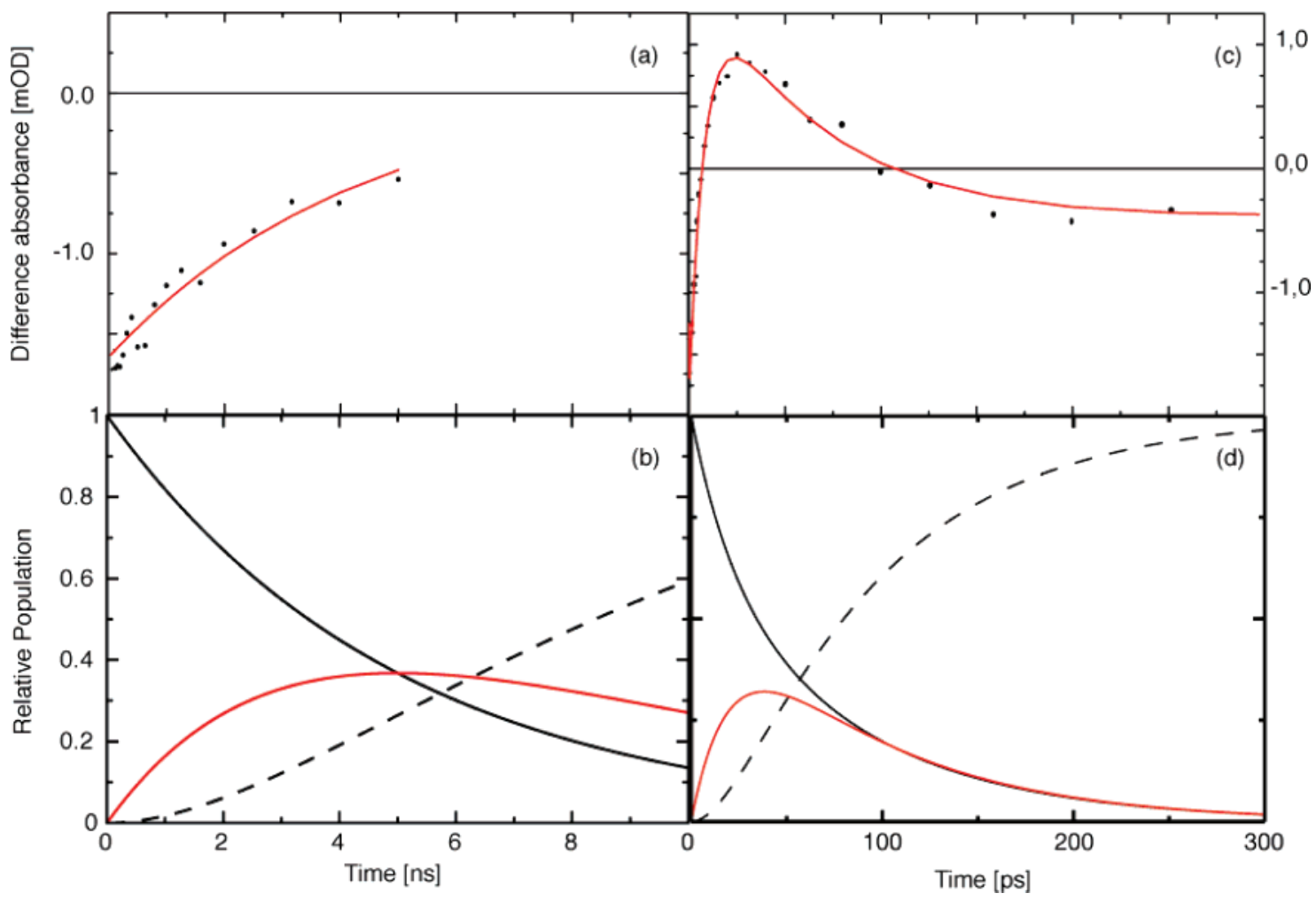

Figure 12. Transient absorbance probing radical formation in 5'-GAX (a) and 5'-ZAX (c) together with simulations of their relative population in $5^{\prime}$-GAX (b) and 5'-ZAX (d) based on the equilibrium model with the following notations: ${ }^{1}\left(\mathrm{X}^{+}\right) *$ (black line), $\mathrm{X}^{\bullet}$ (red line), and $\mathrm{X}^{+}($dashed line).

transfer in small $\pi$ stacked DNA complexes have been performed. ${ }^{74}$ They show that charge transfer parameters of the radical cation systems can be estimated well at the HartreeFock level within the approximation of Koopmans' theorem, allowing for the use of the highest occupied molecular orbitals (HOMOs) of a neutral system. Thus, in the present work, we carried out Hartree-Fock and density functional theory (DFT) calculations of several nucleobase complexes using the 6-31G* basis set and the program Gaussian $03 .{ }^{74}$

Chromophore. Calculations were performed on the acridinium chromophore $\mathrm{X}^{+}$(see also Chart 1). Its geometry was optimized using DFT calculations (the B3LYP/6-31G* scheme).

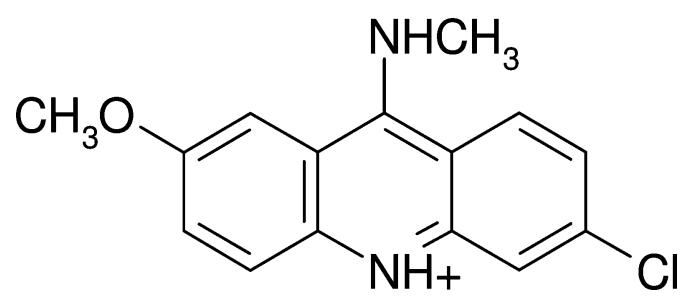

We computed the ground and excited states of the system using the CIS INDO/S approach. ${ }^{76} \mathrm{We}$ accounted for configurational interaction of 400 singly excited states within the active space consisting of 20 HOMOs and 20 LUMOs.

Estimation of Electronic Couplings. In order to calculate charge transfer energetics and electronic couplings, we used molecular orbitals corresponding to the "+" and "-" combinations of the donor and acceptor states. The generalized Mulliken-Hush method ${ }^{77,78}$ was employed. The computational procedure has been described in detail elsewhere. ${ }^{79}$

Internal Reorganization Energy. The internal reorganization energy $\left(\lambda_{\mathrm{i}}\right)$ was calculated at the B3LYP/6-31G* level; for radical cation states, the unrestricted Kohn-Sham method was applied. By definition, $\lambda_{\mathrm{i}}$ for the hole transfer reaction between two species, $\mathrm{M}_{1}^{+}+\mathrm{M}_{2} \rightarrow \mathrm{M}_{1}+\mathrm{M}_{2}{ }^{+}$, turns out to be a sum of the reorganization energies of the subunits. To estimate $\lambda_{i}$ for a molecule, M, the following terms were computed: (1) the energy $E_{0}(\mathrm{M})$ of neutral $\mathrm{M}$ at the optimized geometry, (2) the energy $E_{+}\left(\mathrm{M}^{+}\right)$of the corresponding cation radical at the optimized geometry, (3) the energy $E_{+}(\mathrm{M})$ of neutral $\mathrm{M}$ calculated at the geometry of the cation radical $\left(\mathrm{M}^{+}\right)^{\bullet}$, and (4) the energy $E_{0}\left(\mathrm{M}^{+}\right)$of the cation-radical state at the geometry of the corresponding neutral molecule $\mathrm{M}$. Thus, the reorganization energy $\lambda_{\mathrm{i}}(\mathrm{M})$ becomes

$$
\lambda_{\mathrm{i}}(\mathrm{M})=\frac{1}{2}\left[E_{+}(\mathrm{M})-E_{+}\left(\mathrm{M}^{+}\right)+E_{0}\left(\mathrm{M}^{+}\right)-E_{0}(\mathrm{M})\right]
$$

Supporting Information Available: Melting points and NMR and femtosecond kinetic data. This material is available free of charge via the Internet at http://pubs.acs.org.

\section{References and Notes}

(1) Eley, D. D.; Spivey, D. I. Faraday Soc. Trans. 1962, 58, 411.

(2) Murphy, C. J.; Arkin, M. R.; Yenkins, Y.; Ghatlia, N. D.; Bossmann, S. H.; Turro, N. J.; Barton, J. K. Science 1993, 262, 1025.

(3) (a) Hall, D. B.; Holmlin, E.; Barton, J. K. Nature 1996, 382, 731.

(b) Hall, D. B.; Barton, J. K. J. Am. Chem. Soc 1997, 119, 5045.

(4) Gasper, S. M.; Schuster, G. B. J. Am. Chem. Soc. 1997, 119, 12762.

(5) Long-range ET in DNA; Schuster, G. B., Ed.; Topics in Current Chemistry 236 and 237; Springer: Berlin, 2004.

(6) Charge Transfer in DNA; Wagenknecht, H.-A., Ed.; Wiley-VCH Weinheim, Germany, 2005.

(7) Seidel, C. A. M.; Schulz, A.; Sauer, M. E. M. J. Phys. Chem. 1996, 100,5541

(8) Steenken, S.; Jovanovich, S. V. J. Am. Chem. Soc. 1997, 119, 617.

(9) Meggers, E.; Michel-Beyerle, M. E.; Giese, B. J. Am. Chem. Soc. 1998, 120, 12950 .

(10) (a) Giese, B.; Amaudrut, J.; Köhler, A. K.; Spormann, M.; Wessely, S. Nature 2001, 412, 318. (b) Giese, B. Top. Curr. Chem. 2004, 236, 27. Remark on $n=1$.

(11) Jortmer, J.; Bixon, M.; Langenbacher, T.; Michel-Beyerle, M. E. Proc. Natl. Acad. Sci. U.S.A. 1998, 95, 12759. 
(12) (a) Bixon, M.; Jortner, J. J. Chem. Phys. 2002, 281, 393. (b) Jortner, J.; Bixon, M.; Voityuk, A. A.; Rösch, N. J. Phys. Chem. A 2002, 106, 7599. (c) Bixon, M.; Jortner, J. J. Am. Chem. Soc. 2001, 123, 12556.

(13) (a) Berlin, Y. A.; Burin, A. L.; Ratner, M. A. Chem. Phys. 2002, 275, 61. (b) Berlin, Y. A.; Kurnikov, I. V.; Beratan, D.; Ratner, M. A.; Burin, A. L. Top. Curr. Chem. 2004, 237, 1

(14) (a) Bruinsma, R.; Gruner, G.; D’Orsogna, M. R.; Rudnick, J. Phys. Rev. Lett. 2000, 85, 4393. (b) Tran, P.; Alavi, B.; Gruner, G. Phys. Rev. Lett. 2000, 85, 1564. (c) Yu, Z. G.; Song, X. Phys. Rev. Lett. 2001, 86 6018. (d) Troisi, A.; Orlandi, G. J. Phys. Chem. B. 2002, 106, 2093. (e) Renger, T.; Marcus, R. A. J. Phys Chem. A 2003, 107, 8404. (f) Conwell E. Top. Curr. Chem. 2004, 237, 73. (g) Schuster, G. B.; Landman, U. Top. Curr. Chem. 2004, 236, 139. (h) Voityuk, A. A.; Siriwong, K.; Rösch, N. Angew. Chem. Int. Ed. 2004, 43, 624.

(15) (a) Lewis, F. D.; Wu, T.; Zhang, Y.; Letsinger, R. L.; Greenfield, S. R.; Wasielewski, M. R. Science 1997, 277, 673. (b) Lewis, F. D. Letsinger, R. L.; Wasielewski, M. R. Acc. Chem. Res. 2001, 34, 159. (c) Lewis, F. D.; Wasielewski, M. R. Top. Curr. Chem. 2004, 236, 45.

(16) (a) Fukui, K.; Morimoto, M.; Segawa, H.; Tanaka, K.; Shimidzu, T. Bioconjugate Chem. 1996, 7, 349. (b) Fukui, K.; Tanaka, K. Nucleic Acids Res. 1996, 24, 3962. (c) Fukui, K.; Tanaka, K. Angew. Chem. 1998 110, 167. (d) Fukui, K.; Tanaka, K.; Fujitsuka, M.; Watanabe, A.; Ito, O. J. Photochem. Photobiol., B 1999, 50, 18.

(17) (a) Hess, S.; Götz, M.; Davis, W. B.; Michel-Beyerle, M. E. J. Am. Chem. Soc. 2001, 123, 10046. (b) Davis, W. B.; Hess, S.; Naydenova, I.; Haselsberger, R.; Ogrodnik, A.; Newton, M. D.; Michel-Beyerle, M. E. J. Am. Chem. Soc. 2002, 124, 2422.

(18) Bixon, M.; Jortner, J. Adv. Chem. Phys. 1999, 106, 35.

(19) (a) Wan, C. Z.; Fiebig, T.; Kelley, S. O.; Treadway, C. R.; Barton, J. K.; Zewail, A. H. Proc. Natl. Acad. Sci. U.S.A. 1999, 96, 6014. (b) O’Neill, M.; Becker, H. C.; Wan, C.; Barton, J. K.; Zewail, A. H. Angew. Chem. Int. Ed. 2003, 42, 5896. (c) Valis, L.; Wang, Q.; Raytchev, M.; Buchvarov, I.; Wagenknecht, H.-A.; Fiebig, T. Proc. Natl. Acad. Sci. U.S.A. 2006, 103, 10192

(20) David, A.; Bleimling, C.; Lehn, J.-M.; Weinhold, E.; TeuladeFichou, M.-P. ChemBioChem 2003, 4, 1326.

(21) Alberti, P.; Ren, J.; Teulade-Fichou, M.-P.; Guittat, L.; Riou, J.F.; Chaires, J. B.; Hélène, C.; Vigneron, J.-P.; Lehn, J.-M.; Mergny, J.-L. J. Biomol. Struct. Dyn. 2001, 19, 505.

(22) Vogtherr, M.; Grimme, S.; Elshorst, B.; Jacobs, D. M.; Fiebig, K.; Griesinger, C.; Zahn, R. J. Med. Chem. 2003, 46, 3563

(23) Montenay-Garestier, T.; Sun, J. S.; Chomilier, J.; Mergny, J. L.; Takasugi, M.; Asseline, U.; Thuong, N. T.; Rougée, M.; Hélène, C. Molecular Basis of Specificity in Nucleic Acid-Drug Interactions; Kluwer Academic Publisher: London, 1990.

(24) Kelley, S. O.; Barton, J. K. Chem. Biol. 1998, 5,413.

(25) Lewis, F. D.; Liu, J.; Liu, X.; Zuo, X.; Hayes, R. T.; Wasielewski, M. R. Angew. Chem. Int. Ed. 2002, 41, 1026. 5893.

(26) Nakatani, K.; Dohno, C.; Saito, J. J. Am. Chem. Soc. 2000, 122,

(27) Voityuk, A. A.; Rösch, N., J. Phys. Chem. B 2002, 106, 3013.

(28) Marcus, R. A.; Sutin, N. Biochem. Biophys. Acta 1985, 811, 265.

(29) Miller, J. R.; Calcaterra, T.; Closs, G. L. J. Am. Chem Soc. 1984, 106,3047

(30) Voityuk, A. A.; Jortner, J.; Bixon, M.; Rösch, N. J. Chem. Phys. 2001, 114, 5614.

(31) Ly, D.; Sanii, L.; Schuster, G. B., J. Am. Chem. Soc. 1999, 121, 9400.

(32) Long, Y. T.; Li, C. Z.; Sutherland, T. C.; Chahma, M.; Lee, J. S.; Kraatz, H. B. J. Am. Chem. Soc. 2003, 125, 8724.

(33) Haas, C.; Kräling, K.; Cichon, M.; Rahe, N.; Carell, T. Angew. Chem. Int. Ed. 2004, 43, 1842

(34) Davis, W. B.; Naydenova, I.; Haselsberger, R.; Ogrodnik, A.; Giese,

B.; Michel-Beyerle, M. E. Angew. Chem. Int. Ed. 2000, 112, 3795.

(35) Ito, T.; Rokita, S. E., Angew. Chem. Int. Ed. 2004, 43, 1839.

(36) Piotto, M.; Saudek, V.; Sklenar, V. J. Biomol. NMR 1992, 2, 661.

(37) Sklenar, V.; Piotto, M.; Leppik, R.; Saudek, R. J. Magn. Reson., Ser. A 1993, 102, 214.

(38) Aue, W. P.; Bartholdi, E.; Ernst, R. R. J. Chem. Phys. 1976, 64 2229.

(39) Kessler, H.; Gehrke, M.; Griesinger, C. Angew. Chem. Int. Ed. 1988 27, 490 .

(40) Haigh, C. W.; Mallion, R. B. Org. Magn. Reson. 1972, 4, 203228.

(41) Abraham, A. J.; Canton, M.; Reid, M.; Griffiths, L. J. Chem. Soc., Perkin Trans. 2 2000, 803.

(42) Abraham, R. J.; Reid, M. J. Chem. Soc., Perkin Trans. 2 2002, 1081.

(43) Wüthrich, K. NMR of Proteins and Nucleic Acids; Wiley: New York, 1986.

(44) Kummer, A. D.; Wiehler, J.; Schüttrigkeit, T. A.; Berger, B. W.; Steipe, B.; Michel-Beyerle, M. E., ChemBioChem 2002, 3, 359.
(45) Pöllinger, F.; Musewald, C.; Heitele, H.; Michel-Beyerle, M. E.; Anders, C.; Futscher, M.; Voit, G.; Staab, H. A. Ber. Bunsen-Ges. Phys. Chem. 1996, 100, 2076

(46) Lossau, H.; Kummer, A.; Heinecke, R.; Pöllinger-Dammer, F.; Kompa, C.; Bieser, G.; Johnsson, T.; Silva, C. M.; Yang, M. M.; Youvan, D. C.; Michel-Beyerle, M. E. Chem. Phys. 1996, $213,1$.

(47) Sun, J.; Rougée, M.; Delarue, M.; Montenay-Garestier, T.; Hélène, C. J. Phys. Chem. 1990, 94, 968 .

(48) (a) Van den Veen, F. J. M.; Hilbers, C. W. Nucleic Acids Res 1988, 16, 5713. (b) Van den Veen, F. J. M.; Hilbers, C. W. Eur. J. Biochem. 1988, 178,1

(49) Coppel, Y., J.; Constant, J.-F.; Coulombeau, C.; Demeunynck, M.; Garcia, J.; Lhomme, J. Biochemistry 1997, 36, 4831.

(50) Lhomme, J.; Constant, J.-F.; Demeunynck, M. Biopolymers 1999, 52,65 .

(51) Lancelot, G.; Guesnet, J.-L.; Asseline, U.; Thuong, N. T. Biochemistry 1988, 27, 1265 .

(52) Lancelot, G.; Thuong, N. T. Biochemistry 1986, 25, 5357.

(53) Guesnet, J.-L.; Vovelle, F.; Thuong, N. T.; Lancelot, G. Biochemistry 1990, 29, 4982 .

(54) Sun, J.-S.; François, J.-C.; Montenay-Garestier, T.; Saison-Behmoaras, T.; Roig, V.; Thuong, N. T.; Hélène, C. Proc. Natl. Acad. Sci. U.S.A. 1989, 86, 9198 .

(55) Hess, S. Dissertation, Technische Universität München, 2002.

(56) Davis, W. B.; Voityuk, A. A.; Rösch, N.; Michel-Beyerle, M. E.; Ernsting, N. P.; Kovalenko, S. A.; Péres, Z.; Lustres, J. L. ChemPhysChem 2002, 3, 452 .

(57) Lewis, F. D.; Zhu, H.; Daublain, P.; Fiebig, T.; Raytchev, M.; Wang, Q.; Shafirovich, V. J. Am. Chem. Soc. 2006, 128, 791.

(58) Wan, C., Fiebig, T., Schiemann, O., Barton, J. K., Zewail, A. H. Proc. Natl. Acad. Sci. U.S.A. 2000, 97, 14052.

(59) The radiative lifetime of ${ }^{1}\left(\mathrm{X}^{+}\right)^{*}=26 \mathrm{~ns}$ has been estimated from the absorption spectrum on the basis of the extinction coefficient of $10^{4}$ $\mathrm{M}^{-1} \mathrm{~cm}^{-1}$ and assuming a refractive index of 1.5 within the base staple (Wilson, W. D.; Lopp, I. G. Biopolymers 1979, 18, 3025. Yang, L.; Weerasinghe, S.; Smith, P. E.; Pettitt, B. M. Biophys. J. 1995, 69, 1519. Markeliz, A. G.; Roitberg, A.; Heilweil, E. J. Chem. Phys. Lett. 2000, 320).

(60) During the $20 \mathrm{~ns}$ lifetime of ${ }^{1}\left(\mathrm{X}^{+}\right)^{*}$, fluorescence quenching by oxygen could in principle open a pathway for photochemical decomposition of the acridinium. In contrast to $\mathrm{X}^{+}$free in aqueous solution, neither the excited state lifetime of the 5'-AAX duplex changed upon the removal of oxygen nor did any signs of photodecomposition develop even after extensive excitation with a high photon flux density. This inertness points to a strongly reduced access of oxygen to intercalated $\mathrm{X}^{+}$, confirming previous observations (Zinger, D.; Geacintov, N. E. Photochem. Photobiol. 1988, 47, 181)

(61) Previous transient absorption experiments ${ }^{17 a}$ with a response function of $3.7 \mathrm{~ns}$ (fwhm) did not allow biexponential kinetics on the timescale of a few nanoseconds to be identified

(62) Due to the superposition of excited state and radical absorption at wavelengths between 550 and $700 \mathrm{~nm}$, dual decay kinetics of ${ }^{1}\left(\mathrm{X}^{+}\right)^{*}$ as observed in time-resolved fluorescence could not be resolved. ${ }^{17}$

(63) Peon, J.; Zewail, A. H. Chem. Phys. Lett. 2001, 348, 255.

(64) The activation (free) energy, $E_{\mathrm{a}}{ }^{\ddagger}=(\lambda+\Delta G)^{2} / 4 \lambda \approx(\lambda / 4+\Delta G /$ $2)$, gives for the ratio between the two rate constants (implying invariant reorganization energies) the relation $k_{\mathrm{B}} T \ln \left[k_{1 \mathrm{~F}}\left(5^{\prime}-\mathrm{ZAX}\right) / k_{1 \mathrm{~F}}\left(5^{\prime}-\mathrm{GAX}\right)\right] \approx$ $1 / 2\left[\Delta G\left(5^{\prime}-\mathrm{GAX}\right)-\Delta G\left(5^{\prime}-\mathrm{ZAX}\right)\right]$. This relation (which was introduced in this form in Christensen, H. E. M.; Ulstrup, J.; Sykes, A. G. Biochim. Biophys. Acta 1990, 1039, 94) is well satisfied for the rate constant ratio of 250 and the driving force difference of the two systems of $0.3 \mathrm{eV}$.

(65) Fan, P.; Härd, T.; Kearns, D. R. J. Phys. Chem. 1989, 93, 6615.

(66) Ni, Y.; Kearns, D. R. J. Phys. Chem. 1989, 93, 6622

(67) Tomasi, J.; Persico, M. Chem. Rev. 1994, 94, 2027.

(68) Voityuk, A. A. J. Phys. Chem. C 2007, 111, 7207.

(69) (a) Bixon, M.; Jortner, J. Chem. Phys. 2002, 281, 393; (b) 2006, $326,252$.

(70) (a) Marcus, R. A. J. Chem. Phys. 1965, 9, 259. (b) Marcus, R. A. J. Chem. Phys. 1957, 26, 867. (c) Marcus, R. A. Discuss. Faraday Soc. 1960, 29, 21.

(71) (a) Kestner, N. R.; Logan, J.; Jortner, J. J. Phys. Chem. 1974, 78, 2148. (b) Ephrema, S.; Bixon, M. Chem. Phys. Lett. 1974, 25, 34. (c) Ulstrup, J.; Jortner, J. J. Chem. Phys. 1975, 63, 4358. (d) Jortner, J. J. Chem. Phys. 1976, 64, 4860.

(72) Weiss, E. A.; Tauber, M. J.; Kelley, R. F.; Ahrens, M. J.; Ratner, M. A.; Wasielewski, M. R. J. Am. Chem. Soc. 2005, 127, 11842.

(73) Heitele, H.; Pöllinger, F.; Häberle, T.; Michel-Beyerle, M. E.; Staab, H. A. J. Phys. Chem. 1994, $98,7402$.

(74) Blancafort, L.; Voityuk A. A. J. Phys. Chem. A 2006, 110, 6426 (75) Frisch, M. J.; Trucks, G. W.; Schlegel, H. B.; Scuseria, G. E.; Robb M. A.; Cheeseman, J. R.; Montgomery, J. A.; Vreven, T.; Kudin, K. N.; Burant, J. C.; Millam, J. M.; Iyengar, S. S.; Tomasi, J.; Barone, V.; Mennucci, B.; Cossi, M.; Scalmani, G.; Rega, N.; Petersson, G. A.; Nakatsuji, H.; Hada, M.; Ehara, M.; Toyota, K.; Fukuda, R.; Hasegawa, J.; 
Ishida, M.; Nakajima, T.; Honda, Y.; Kitao, O.; Nakai, H.; Klene, M.; Li, X.; Knox, J. E.; Hratchian, H. P.; Cross, J. B.; Adamo, C.; Jaramillo, J.; Gomperts, R.; Stratmann, R. E.; Yazyev, O.; Austin, A. J.; Cammi, R.; Pomelli, C.; Ochterski, J. W.; Ayala, P. Y.; Morokuma, K.; Voth, G. A.; Salvador, P.; Dannenberg, J. J.; Zakrzewski, V. G.; Dapprich, S.; Daniels, A. D.; Strain, M. C.; Farkas, O.; Malick, D. K.; Rabuck, A. D.; Raghavachari, K.; Foresman, J. B.; Ortiz, J. V.; Cui, Q.; Baboul, A. G.; Clifford, S.; Cioslowski, J.; Stefanov, B. B.; Liu, G.; Liashenko, A.; Piskorz, P.; Komaromi, I.; Martin, R. L.; Fox, D. J.; Keith, T.; Al-Laham, M. A.;
Peng, C. Y.; Nanayakkara, A.; Challacombe, M.; Gill, P. M. W.; Johnson, B.; Chen, W.; Wong, M. W.; Gonzalez, C.; Pople, J. A. Gaussian 03, revision B.02; Gaussian, Inc.: Pittsburgh, PA, 2003.

(76) Ridley, J. E., Zerner, M. C. Theor. Chim. Acta 1973, 15, 134.

(77) Cave, R. J.; Newton, M. D. J. Chem. Phys. 1997, 106, 9213

(78) Cave, R. J.; Newton, M. D. Chem. Phys. Lett. 1996, 249, 15.

(79) Voityuk, A. A. In Computational studies of RNA and DNA; Śponer, J., Lankas, F., Eds.; Springer: Dordrecht, The Netherlands, 2006; pp 485512 . 